\title{
Symbionts in waiting: the dynamics of incipient endosymbiont complementation and replacement in minimal bacterial communities of psyllids
}

\author{
Jennifer L. Morrow ${ }^{1}$, Aidan A. G. Hall ${ }^{1,2}$ and Markus Riegler ${ }^{1 *}$ (B)
}

\begin{abstract}
Background: Obligate bacterial primary (P-) endosymbionts that are maternally inherited and codiverge with hosts are widespread across insect lineages with nutritionally restricted diets. Secondary (S-) endosymbionts are mostly facultative, but in some hosts, they complement P-endosymbiont function and therefore become obligate. Phylogenetic evidence exists for host switching and replacement of S-endosymbionts. The community dynamics that precede endosymbiont replacement and complementation have been little studied across host species, yet they are fundamental to the evolution of endosymbiosis.
\end{abstract}

Results: We performed bacterial 16S rRNA gene amplicon sequencing of 25 psyllid species (Hemiptera, Psylloidea) across different developmental stages and ecological niches by focusing on the characterisation of the bacteria other than the universally present P-endosymbiont Carsonella (Gammaproteobacteria). Most species harboured only one dominant representative of diverse gammaproteobacterial S-endosymbionts that was consistently detected across all host individuals and populations (Arsenophonus in eight species, Sodalis or Sodalis-like bacteria in four species, unclassified Enterobacteriaceae in eight species). The identity of this dominant obligate S-endosymbiont varied across closely related host species. Unexpectedly, five psyllid species had two or three co-occurring endosymbiont species other than Carsonella within all host individuals, including a Rickettsiella-like bacterium (Gammaproteobacteria) in one psyllid species. Based on standard and quantitative PCR, all psyllids carried Carsonella, at higher titres than their dominant S-endosymbionts. Some psyllids also had Alphaproteobacteria (Lariskella, Rickettsia, Wolbachia) at varying prevalence. Incidence of other bacteria, including known plant pathogens, was low. Ecological niche of gall-forming, lerp-forming and free-living psyllid species did not impact endosymbiont communities. Two flush-feeding psyllid species had population-specific differences, and this was attributable to the higher endosymbiont diversity in native ranges and the absence of some endosymbionts in invasive ranges.

Conclusions: Our data support the hypothesis of strict vertical transmission of minimal core communities of bacteria in psyllids. We also found evidence for S-endosymbiont replacement across closely related psyllid species. Multiple dominant S-endosymbionts present in some host species, including at low titre, constitute potential examples of incipient endosymbiont complementation or replacement. Our multiple comparisons of deep-sequenced minimal insect bacterial communities exposed the dynamics involved in shaping insect endosymbiosis.

Keywords: Core microbiota, Symbiosis, Endosymbiont replacement, Carsonella, Psyllid, Arsenophonus, Sodalis, Enterobacteriaceae, Plant pathogenic bacteria, Insect

\footnotetext{
* Correspondence: m.riegler@westernsydney.edu.au

${ }^{1}$ Hawkesbury Institute for the Environment, Western Sydney University,

Locked Bag 1797, Penrith, NSW 2751, Australia

Full list of author information is available at the end of the article
} 


\section{Background}

Animals' diverse interactions with bacterial symbionts can sit anywhere on the scale from parasitism to mutualism, including interactions of invertebrates with maternally inherited intracellular bacterial endosymbionts that provide fitness benefits to hosts. Endosymbiosis can result in genome size reduction of bacterial symbionts and their loss of function [1], requiring complementation or replacement by other endosymbionts [2, 3]. Prior to this, host switches and acquisition of endosymbionts must occur, but these processes have not been studied for entire bacterial communities across many host species. Insects with minimal bacterial communities consisting of a few core species may provide excellent model systems to investigate these symbiont community dynamics.

Insects that feed on plant sap or other nutritionally restricted diets depend on nutrient provisioning by primary (P-) endosymbionts that are localised within specialised host cells and omnipresent in host populations due to the efficient and strictly maternal endosymbiont transmission. This results in co-evolution and can be seen in the phylogenetic congruency of bacterial endosymbionts and hosts [4]. In contrast to obligate Pendosymbionts, many host insects also have facultative associations with other bacteria, secondary (S-) endosymbionts, which may provide fitness benefits to hosts only in a certain ecological or environmental context [5-8]. S-endosymbionts exhibit some key features that are shared with P-endosymbionts: they are intracellular, mostly vertically transmitted (with occasional horizontal transmission), and in some instances fixed in host populations [9]. Furthermore, the genomes of P- and many Sendosymbionts have reduced genome sizes, symptomatic of long-term, obligate endosymbiosis, combined with signs of functional complementation signifying a seemingly stable coexistence of both types of endosymbionts with the host $[10,11]$. Endosymbionts are placed under diverse selection pressures, directly from the intracellular host environment [12], and indirectly through environmental and ecological factors such as climate, host plant choice, plant use and plant defences that act on their insect host $[13,14]$. Conversely, endosymbiosis drives the evolution of endosymbiont genomes towards accelerated mutation rates and the accumulation of non-lethal mutations [15], gene loss and sometimes lateral gene transfer to the host genome [16]. This may necessitate complementation of P-endosymbiont function by facultative $\mathrm{S}$ endosymbionts that can then become obligate to hosts $[3,10]$. It can also result in the loss and replacement of established S-endosymbionts after the acquisition of new endosymbionts by horizontal transmission as evidenced by incongruent phylogenies between S-endosymbionts and hosts [3, 17-21]. Incipient endosymbiont replacement may be detected in hosts containing multiple endosymbionts at varying prevalence within species or varying incidence across related species. Only a few studies have comprehensively characterised entire bacterial communities of hosts both within and across a significant number of species $[9,22]$, yet such studies are required to detect all present bacteria in hosts, including bacterial symbionts that may evolve from an indifferent transient role (as perhaps seen by a low prevalence or low bacterial titre) to a mutualistic role in their hosts (and they could be referred to as 'symbionts in waiting').

Many hemipterans, including plant sap-feeding insects such as aphids, whiteflies and psyllids, have evolved a specialised abdominal tissue structure, the bacteriome, where $\mathrm{P}$ - and S-endosymbionts reside. The bacteriome usually consists of bacteriocytes surrounded by a multinucleate syncytium [23]. All species of the hemipteran superfamily Psylloidea (in a broad sense referred to as psyllids) harbour the obligate, maternally inherited Pendosymbiont 'Candidatus Carsonella ruddii' (hereafter Carsonella; Gammaproteobacteria) [24]. According to in situ hybridisation studies of the mulberry psyllid, Anomoneura mori, and the Asian citrus psyllid, Diaphorina citri, Carsonella is housed in vesicles within the bacteriocytes, while the S-endosymbionts are localised to the syncytial region [25-27], confirming early microscopic observations of both P- and S-endosymbionts of psyllids [28]. Carsonella has an AT-rich and very small genome of approximately $160 \mathrm{~kb}$, with few remaining genes involved in DNA repair, energy metabolism and cell envelope synthesis, as well as having lost complete or partial amino acid synthesis pathways [10, 29]. As a consequence of the minimal genome of Carsonella and its reduction in the number of encoded enzymes for amino acid synthesis, it has been predicted that complementing S-endosymbionts may be just as essential to psyllid fitness as the P-endosymbiont [10].

In some hosts, S-endosymbionts show typical signs of obligate mutualism, whereas closely related bacteria found in other host lineages are facultative and do not exhibit extreme gene loss and efficient maternal transmission [30]. For example, whole genome assembly of the Enterobacteriaceae S-endosymbionts of the psyllids Ctenarytaina eucalypti and Heteropsylla cubana revealed signs of genome reduction, AT bias and metabolic complementarity with the associated Carsonella strain [10]. However, unlike Carsonella that codiverges with its host, these Sendosymbionts have not strictly codiverged across the entire host phylogeny: while some psyllid lineages appear to show signs of co-evolution with obligate $\mathrm{S}$ endosymbionts [31], there is also evidence for multiple host switching events of obligate S-endosymbionts across several psyllid genera [3, 17], and a few gallforming psyllid species were reported to exist without any detectable S-endosymbionts [10, 29, 32]. 
Psyllid species occupy different ecological niches during their nymphal development [33], and this may shape their microbiota. Psyllid nymphs can be free-living, develop within psyllid-induced galls, or develop beneath a 'lerp', a cover constructed from solidified psyllid excretions, which offers a protective enclosure that maintains humidity while also restricting nymphs to a particular feeding spot [34]. Lerp building is a predominantly Australian feature common to approximately $50 \%$ of Australian psyllid species [35] and could be seen as a transition from the free-living to the gall-forming niche space. The protective and nutritionally enhanced environment of the gall over lerp and free-living niches may reduce endosymbiont reliance of psyllids or influence the type of microbial associations; indeed, studies of gall-forming psyllids have suggested that this may be the reason for the absence of detectable S-endosymbionts in gall-forming Pachypsylla spp. and Cecidotrioza [10, 32]. However, these are the only genera for which a complete absence of S-endosymbionts has been reported, and another gall-forming psyllid, Trioza eugeniae (which forms a pit gall, unlike the enclosed gall of Pachypsylla and Cecidotrioza), was found to harbour a S-endosymbiont [3]. Furthermore, gall forming is not exclusive to any particular psyllid family, is found in several lineages and has arisen independently: for example, most species of Glycaspis (family Aphalaridae) build lerps, but some nymphs of the subgenus Synglycaspis form pouch galls on their host plants and species of Trioza (family Triozidae) induce galls and pit galls or are free-living [33]. In addition, some psyllid species are considered flush feeders (i.e. they feed on young plant tissue) while others are senescence feeders that favour mature plant tissue [36] and induce early leaf senescence in order to access nutrients that become available due to reallocation within plants [37]. Similar to lerps, apical buds may also provide eggs and nymphs of free-living psyllids with a more enclosed environment that reduces risk of desiccation [38]. It has been found that these different ecological niches impact psyllid life histories and population dynamics [39] and may influence the propensity of different psyllids to acquire and vector plant pathogenic bacteria [40] and, perhaps, other psyllid microbiota.

To investigate the diversity and composition of Sendosymbionts across host lineages, potential signatures of incipient symbiont complementation or replacement and the influence of the nutritional environment in which nymphs develop, we performed high-throughput $16 \mathrm{~S}$ rRNA gene amplicon sequencing on nymphs and adults of 25 species of 11 genera of four of the eight families of Psylloidea as classified by Burckhardt and Ouvrard [41]. Table 1 describes the specific aims for this study, utilising psyllid species that differ by host plant specialisation (eucalypts and other host plants), geographic locations (including both native and invasive ranges for some species) and ecological niche (free-living, gallforming and lerp-building species with representation of flush and senescence feeders).

\section{Methods}

\section{Psyllid collection and characterisation}

Psyllid nymphs and adults were sampled from 25 species of 11 genera of four families within Psylloidea, from host plants mostly in Australia (Fig. 1, Table 2, Additional file 1). Individuals of three species that are invasive outside their Australian-native range were obtained from Portugal, and individuals of one North American species were collected in the USA. One focus of this study was a genus of lerp-building psyllids, Cardiaspina, which strictly feed on Eucalyptus; some Cardiaspina species are significant defoliators and therefore of ecological and economic importance [39, 42]. These were contrasted with other psyllid genera that form distinctive lerps, are free-living or gall-formers (ecology: niche; Table 2), are defined as flush- or senescence feeders [42] (ecology: feeding; Table 2), and developed on the eucalypt genera Eucalyptus or Corymbia or non-eucalypt trees and shrubs including Allocasuarina, Brachychiton, Solanum, Ficus, Syzygium and Persea (host plant; Table 2). The genus Cardiaspina is represented by seven described species and an eighth yet unassigned Cardiaspina species responsible for severe defoliation of Eucalyptus moluccana

Table 1 Experimental aims

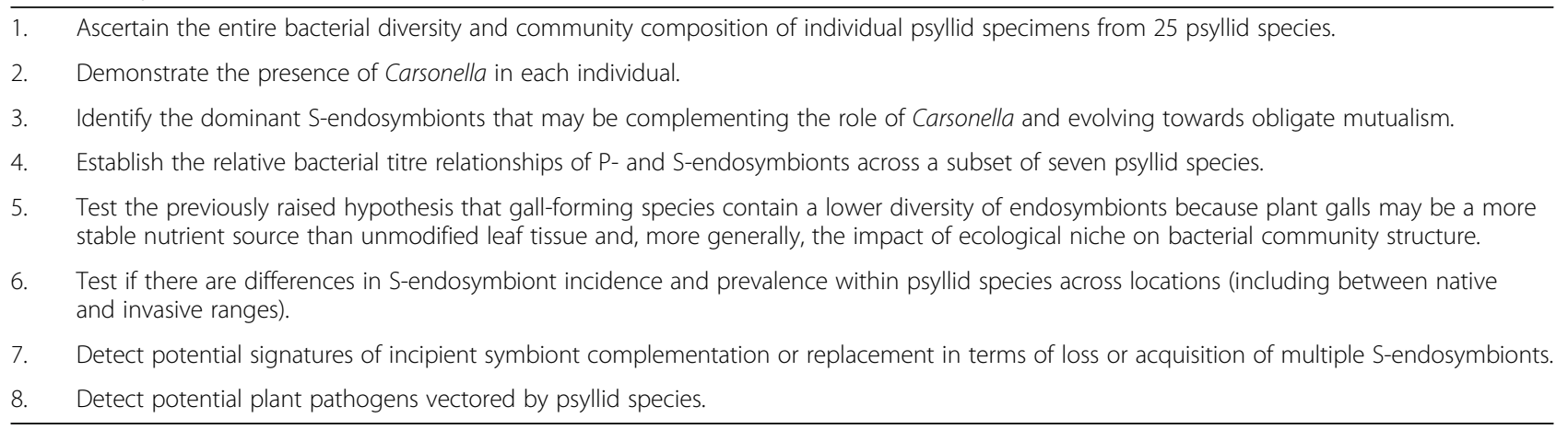




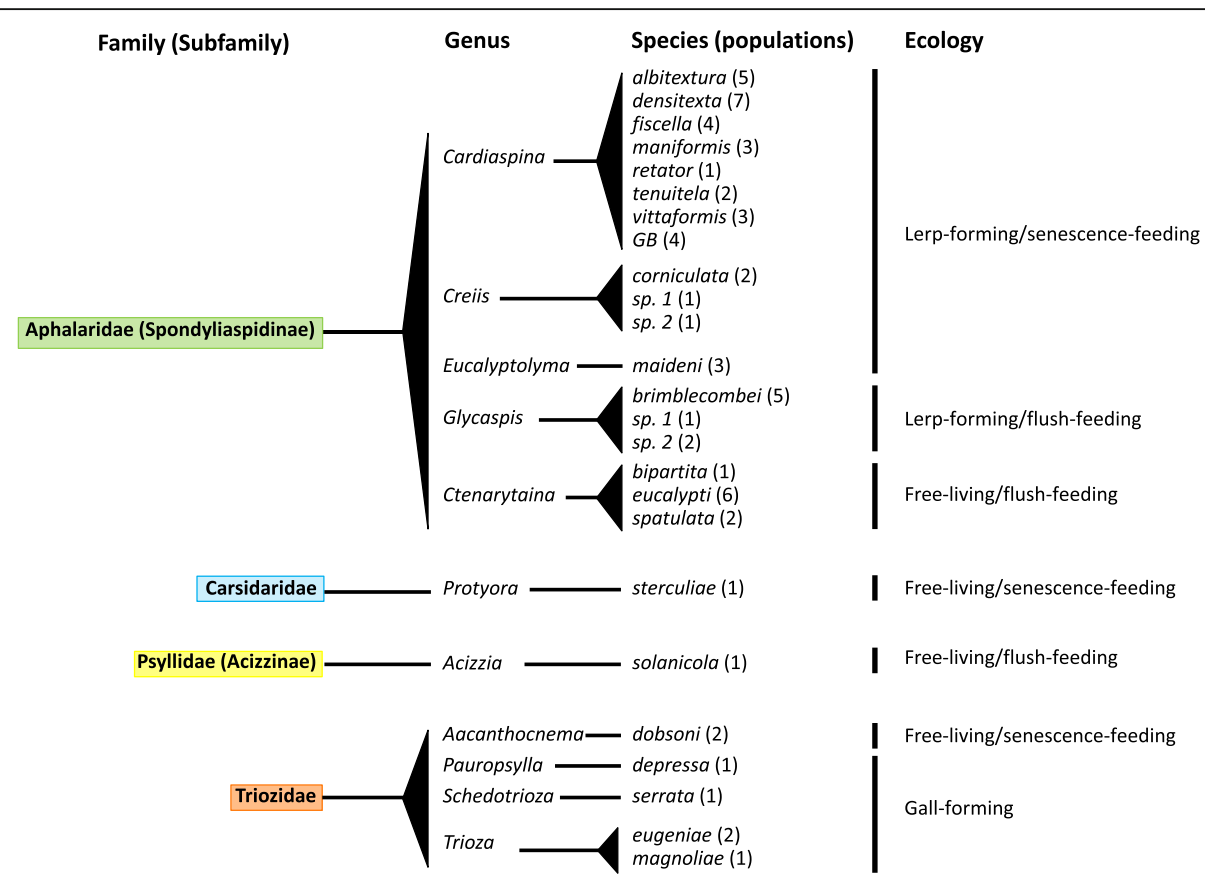

Fig. 1 Schematic representation of the psyllid species included in this study. Current taxonomic classification to family level is shown, as are the number of populations collected and the ecological type of each species. Aphalaridae (highlighted in green) included in this study are associated with eucalypts; the species from the other families are not associated with eucalypts

(Grey Box) and referred to as GB Cardiaspina sp. [43]. The other 10 genera are represented by 13 identified species, in addition to four taxa (two Glycaspis sp. and two Creiis sp.) that were not classified beyond genus level but were collected from different host plant species and had different DNA barcodes.

Leaves with psyllid nymphs were collected and placed into zip-lock bags. Nymphs were then either placed directly from leaf surfaces into microcentrifuge tubes with absolute ethanol or allowed to develop into adult males and females and then stored in absolute ethanol. For each species, three to 19 individuals were selected for DNA extraction. Depending on availability, these were adults (females or males) and/or nymphs (fourth or fifth instar) from one to up to seven populations. All specimens were surface sterilised with $4 \%$ sodium hypochlorite as described in Morrow et al. [44], and DNA was extracted from whole individuals using DNeasy 96 Blood and Tissue kit (Qiagen) including RNase treatment with $0.4 \mathrm{mg}$ RNase (Sigma). DNA quality and yield was assessed by Nanodrop spectrophotometry, Qubit 2.0 Fluorometry and gel electrophoresis. All samples were initially amplified using general eubacterial 16S rRNA gene primers (63F and 1227R [45, 46]; Additional file 2) to check quality of amplification and with insect mitochondrial cytochrome $b$ (CB1 and CB2 [47]) or cytochrome oxidase I primers (Pat and Dick [48] and/or LCO1490 and HCO2140 [49]; Additional file 2). cytB and COI amplicons of all individuals were directly sequenced to assess species identity against submissions in the NCBI GenBank database. Because nymphs can potentially be parasitized by parasitoids [50], all nymph sequences were strictly checked for parasitoid cytb or COI sequences as either the dominant or a background sequence within the chromatogram. Nine individuals amplifying parasitoid DNA were eliminated from the study (Additional file 3). COI and cytb sequences were submitted to GenBank, with accession numbers listed in Additional file 1.

Extracts of high molecular weight and amplifiable DNA were submitted to the HIE Next Generation Sequencing Facility for $16 \mathrm{~S}$ rRNA gene amplification using primers $341 \mathrm{~F}$ and $805 \mathrm{R}$, which encompass the $\mathrm{V} 3-\mathrm{V} 4$ region of the 16S rRNA gene and produce a fragment of approximately $464 \mathrm{bp}$, including primers [44]. Library preparation, inputting $7 \mathrm{ng}$ of DNA extract, was performed using the Nextera XT kit and $2 \times 300$ bp paired-end sequencing on a 384-multiplexed Illumina MiSeq run.

\section{Data analysis using QIIME}

Raw data (fastq format) of 191 individual psyllid libraries were examined using FastQC v0.11.4 (http://www.bioinformatics.babraham.ac.uk/projects/fastqc). Nextera XT libraries are more prone to substitution errors than insertions or deletions, and errors are twice as common in R2 reads compared to R1 reads; thus, trimming at least $10 \mathrm{bp}$ from the 3' ends of the R1 and R2 reads and merging overlapping reads to correct for errors significantly increases accuracy in these libraries [51]. FastQC demonstrated that the 
Table 2 Sampling metadata for the psyllid individuals of 25 species representing four of the eight families within Psylloidea

\begin{tabular}{|c|c|c|c|c|c|c|c|c|}
\hline \multirow[t]{2}{*}{ Family } & \multirow[t]{2}{*}{ Species name } & \multicolumn{2}{|l|}{ Ecology } & \multirow[t]{2}{*}{ Location (collection date) } & \multirow[t]{2}{*}{ Host plant } & \multicolumn{3}{|c|}{ No. of individuals } \\
\hline & & Niche & Feeding & & & Female & Male & Nymph \\
\hline \multirow[t]{36}{*}{ Aphalaridae } & Cardiaspina albitextura & Lerp & Senescence & Mudgee; NSW (2015) & Eucalyptus blakelyi & 3 & & \\
\hline & & & & $\begin{array}{l}\text { Black Mountain Road carpark, } \\
\text { Canberra; ACT (2013) }\end{array}$ & Eucalyptus blakelyi & & & 3 \\
\hline & & & & $\begin{array}{l}\text { Black Mountain Peninsula; } \\
\text { ACT (2013) }\end{array}$ & Eucalyptus blakelyi & 3 & & \\
\hline & & & & $\begin{array}{l}\text { Bruce Ridge Nature Reserve; } \\
\text { ACT (2014) }\end{array}$ & Eucalyptus blakelyi & 3 & & \\
\hline & & & & $\begin{array}{l}\text { Western Sydney U, } \\
\text { Hawkesbury; NSW (2012) }\end{array}$ & Eucalyptus robusta & & & 3 \\
\hline & Cardiaspina densitexta & Lerp & Senescence & $\begin{array}{l}\text { Battunga Road, Echunga; } \\
\text { SA (2013) }\end{array}$ & Eucalyptus fasciculosa & 3 & & \\
\hline & & & & Callington; SA (2013) & Eucalyptus fasciculosa & & & 3 \\
\hline & & & & Bunbury Road, Tintinara; SA (2013) & Eucalyptus fasciculosa & & & 3 \\
\hline & & & & Tiver's Road, Spence; SA (2013) & Eucalyptus fasciculosa & & & 3 \\
\hline & & & & $\begin{array}{l}\text { Hampton Road, Naracoorte; } \\
\text { SA (2013) }\end{array}$ & Eucalyptus fasciculosa & & & 3 \\
\hline & & & & $\begin{array}{l}\text { Nolan's Road, Naracoorte; } \\
\text { SA (2013) }\end{array}$ & Eucalyptus fasciculosa & & & 3 \\
\hline & & & & Echunga; SA (2013) & Eucalyptus sp. & & & 1 \\
\hline & Cardiaspina fiscella & Lerp & Senescence & EucFACE, Richmond; NSW (2014) & Eucalyptus tereticornis & 3 & & \\
\hline & & & & Yellowmundee; NSW (2014) & Eucalyptus tereticornis & & & 3 \\
\hline & & & & Cronulla; NSW (2014) & Eucalyptus botryoides & & 2 & 1 \\
\hline & & & & $\begin{array}{l}\text { Rotary Park, Southwest Rocks; } \\
\text { NSW (2013) }\end{array}$ & Eucalyptus botryoides & & & 3 \\
\hline & Cardiaspina maniformis & Lerp & Senescence & $\begin{array}{l}\text { Western Sydney U, Hawkesbury; } \\
\text { NSW (2014) }\end{array}$ & Eucalyptus saligna & 3 & & \\
\hline & & & & Macquarie Fields; NSW (2014) & Eucalyptus tereticornis & 3 & & \\
\hline & & & & Yellowmundee; NSW (2014) & Eucalyptus tereticornis & & & 1 \\
\hline & Cardiaspina retator & Lerp & Senescence & $\begin{array}{l}\text { Battunga Road, Echunga; } \\
\text { SA (2013) }\end{array}$ & Eucalyptus camaldulensis & 1 & 2 & 2 \\
\hline & Cardiaspina tenuitela & Lerp & Senescence & $\begin{array}{l}\text { Mary Lawson Wayside Rest, } \\
\text { Finley; NSW (2013) }\end{array}$ & Eucalyptus melliodora & & & 1 \\
\hline & & & & $\begin{array}{l}\text { Bruce Ridge Nature Reserve; } \\
\text { ACT (2014) }\end{array}$ & Eucalyptus melliodora & 3 & & \\
\hline & Cardiaspina vittaformis & Lerp & Senescence & Doonside; NSW (2012) & Eucalyptus crebra & & & 3 \\
\hline & & & & $\begin{array}{l}\text { Black Mountain CSIRO, } \\
\text { Canberra; ACT (2014) }\end{array}$ & Eucalyptus sideroxylon & & & 3 \\
\hline & & & & Western Sydney; NSW (2012) & Eucalyptus crebra & 3 & & \\
\hline & GB Cardiaspina sp. & Lerp & Senescence & Rossmore Park; NSW (2013) & Eucalyptus moluccana & 3 & & \\
\hline & & & & $\begin{array}{l}\text { Western Sydney U, Hawkesbury; } \\
\text { NSW (2014) }\end{array}$ & Eucalyptus moluccana & 3 & & 2 \\
\hline & & & & Nurragingy Reserve; NSW (2013) & Eucalyptus moluccana & 3 & & \\
\hline & & & & $\begin{array}{l}\text { Dr Charles Mckay Reserve } \\
\text { Blacktown; NSW (2013) }\end{array}$ & Eucalyptus moluccana & 3 & & \\
\hline & Creiis corniculata & Lerp & Senescence & $\begin{array}{l}\text { EucFACE, Richmond; } \\
\text { NSW (2015) }\end{array}$ & Eucalyptus tereticornis & 3 & & \\
\hline & & & & Glen Helen; NT (2012) & Eucalyptus camaldulensis & 3 & & \\
\hline & Creiis sp. 1 & Lerp & Senescence & $\begin{array}{l}\text { EucFACE, Richmond; } \\
\text { NSW (2012) }\end{array}$ & Eucalyptus tereticornis & & & 3 \\
\hline & Creiis sp. 2 & Lerp & Senescence & Ingleburn; NSW (2013) & Eucalyptus paniculata & 3 & & \\
\hline & Ctenarytaina bipartita & Free-living & Flush & Tasman Peninsula; Tasmania (2012) & Eucalyptus sp. & 3 & & \\
\hline & Ctenarytaina eucalypti & Free-living & Flush & Sao Pedro do Sul; Portugal (2011) & Eucalyptus globulus & 3 & & \\
\hline & & & & Oliveira de Azemeis; Portugal (2011) & Eucalyptus globulus & 3 & & \\
\hline
\end{tabular}


Table 2 Sampling metadata for the psyllid individuals of 25 species representing four of the eight families within Psylloidea (Continued)

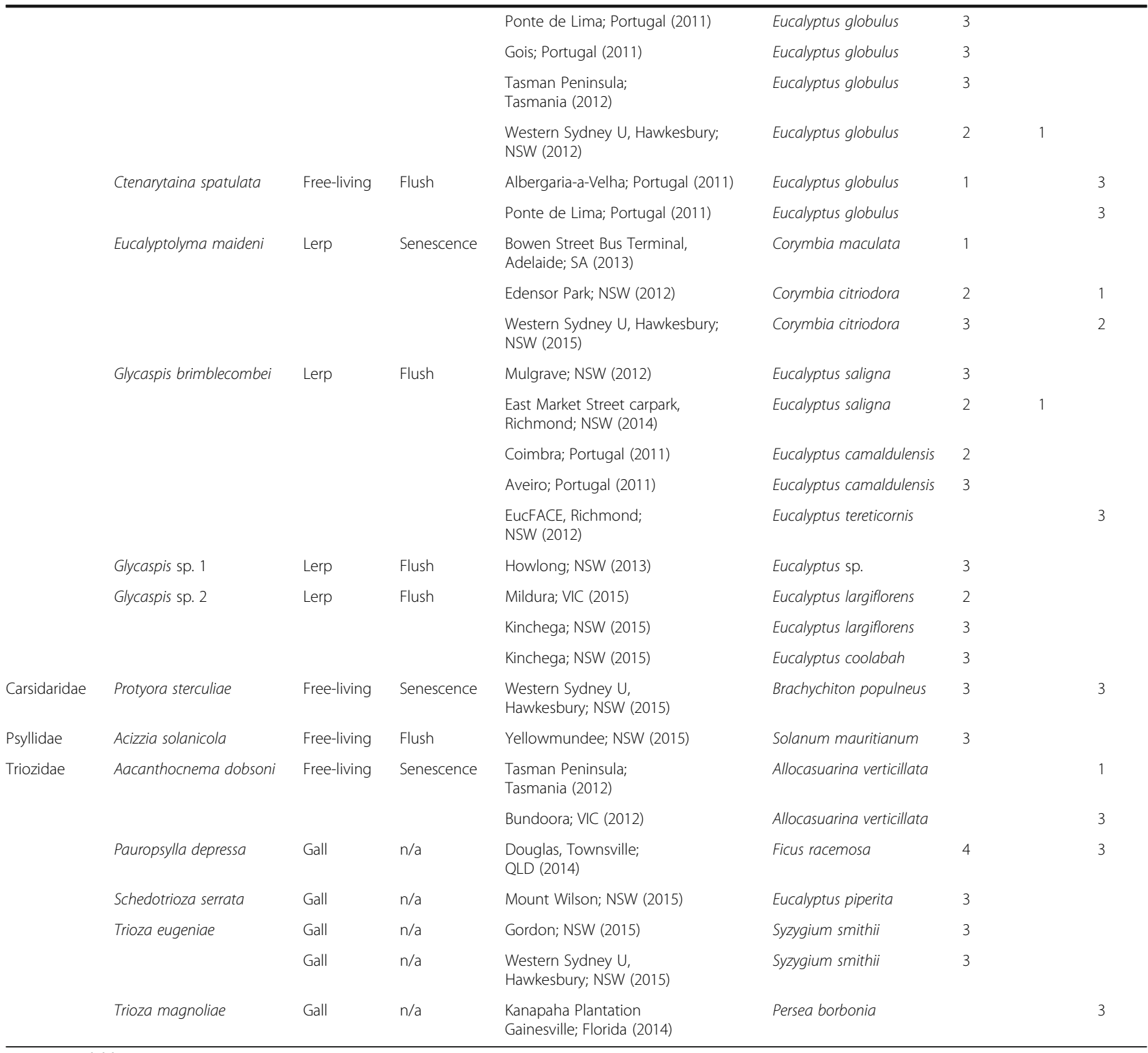

n/a not available

quality of $\mathrm{R} 2$ reads of our dataset deteriorated more than $\mathrm{R} 1$; therefore, the sequences were trimmed using the trimfq command of seqtk (http://github.com/lh3/seqtk), removing primer sequence and the final $10 \mathrm{bp}(-\mathrm{b} 17-\mathrm{e} 10)$ from the forward (R1) reads and and primer and final $90 \mathrm{bp}$ from the R2 reads (-b 21 -e 90). FLASH v1.2.11 (http:// ccb.jhu.edu/software/FLASH/) was implemented with default parameters, and this joined the trimmed, paired reads into single sequences with a minimum overlap of $10 \mathrm{bp}$.

The bacterial community classification and analysis of these samples was performed using QIIME 1.8.0 [52]. Operational taxonomic units (OTUs) were clustered at 97\% sequence similarity to the greengenes 13_8-release database using uclust [53] as implemented by the pick_open_reference_otus.py script using default parameters, except that OTUs comprising fewer than three sequences were removed. No negative controls were included in the sequencing dataset; instead, these low read count OTUs were removed during the OTU picking step, so as not to inflate the bacterial diversity due to sequencing error, while still retaining reads of low relative abundance. Representative sequences were chosen as the cluster seed (default parameter). Chimeras were identified using the blast_fragments method [54]. Rarefaction graphs were generated to determine the optimal number of sequences for normalisation of samples. Alpha diversity 
metrics implemented by 'alpha_diversity.py' included observed species, Chaol (species richness), Shannon and Simpson (diversity) indices and Good's coverage. Beta diversity was analysed using the phylogenetic distancebased measurement, UniFrac: implementing unweighted UniFrac to assess the relationship between presence and absence of taxa and weighted UniFrac to additionally consider relative taxa abundance. Bray-Curtis similarities were assessed for the presence/absence and relative abundance of OTUs. Statistical tests of alpha and beta diversity comparisons by category (species, genus, ecological niche, whether flush or senescence feeders, and host plant type, i.e. eucalypt versus non-eucalypt) were called by compare_alpha_diversity.py and compare_categories.py.

\section{S rRNA gene sequence from whole genome sequencing approaches}

Whole genome sequencing (WGS) of pooled psyllid samples was generated for seven psyllid species: Cardiaspina albitextura, Cardiaspina densitexta, Cardiaspina tenuitela, Cardiaspina fiscella, Cardiaspina maniformis, GB Cardiaspina sp. and Protyora sterculiae. For each species, the bacteriomes from 10 adult females were dissected and pooled and the DNA extracted using QiaAmp Mini DNA Extraction kit (Qiagen). In order to maximise the DNA of the endosymbionts within the sample, whole genomic DNA was amplified by multiple displacement with REPLI-G mini kit (Qiagen). The DNA quality and yield was ascertained using Nanodrop spectrophotometry, Qubit 2.0 Fluorometry and gel electrophoresis. The DNA preparations were then submitted for the generation of Truseq DNA PCR-free libraries (350 bp insert, $2 \times 101 \mathrm{bp}$ paired end) with $1 \mu \mathrm{g}$ input DNA. Four libraries (C. albitextura, $C$. densitexta, $C$. tenuitela and GB Cardiaspina sp.) were run on Illumina Hiseq 1500. The other three libraries were run together with three other libraries on a single lane of Illumina HiSeq2500. The paired fastq output files for each library were imported into CLC Genomics Workbench (ver9.0). Adapters and low-quality reads were removed from the seven libraries by using a trimming function based on the modified Mott algorithm, set to a limit of 0.01. Each library was assembled using default parameters in CLC Workbench. To isolate full-length 16S rRNA gene sequences of Arsenophonus, the whole genome of Arsenophonus nilaparvatae (NZ_JRLH01000000) was BLAST searched against each assembly to identify matching contigs. Similarly, C. maniformis was scanned for sequences matching the Sodalis glossinidius str. 'morsitans' genome (AP008232) and P. sterculiae contigs were identified by BLAST match to the $16 \mathrm{~S}$ rRNA gene of ' $\mathrm{Ca}$ ndidatus Schneideria nysicola' (hereafter Schneideria; HE586114). Complete or near complete 16S rRNA genes were assembled from each library and read mapping performed to ensure accuracy of the sequence and to check for background sequences.

\section{qPCR}

Quantitative PCR was employed to ascertain the relative abundance of the obligate P-endosymbiont Carsonella with the dominant $\mathrm{S}$-endosymbionts in 42 individuals of seven Cardiaspina species. This was done to verify relative quantification provided by high-throughput amplicon sequencing. The primers $341 \mathrm{~F}$ and $805 \mathrm{R}$ used for high-throughput 16S rRNA gene amplicon sequencing were designed to amplify a wide range of bacteria for microbial community studies and contained no mismatches to the known S-endosymbionts of the Cardiaspina psyllids (e.g. Arsenophonus and Sodalis); however, they contained multiple mismatches in both forward and reverse primers to Carsonella, biasing the amplification away from Carsonella. Therefore, for quantification relative to Carsonella and host, primers were designed using PrimerQuest (IDT) to perfectly match the endosymbiont atpA (single copy genes based on published endosymbiont genomes) and host elongation factor 1 alpha (EF1 $\alpha)$ genes for three groups of Cardiaspina species, with groupings based on their phylogenetic relationships [3]: (1) C. densitexta, C. tenuitela, GB Cardiaspina sp. and C. albitextura; (2) C. fiscella and closely related C. retator; and (3) C. maniformis (Additional file 2). Carsonella-and Sodalis-specific atpA primers were designed for C. maniformis, while other Carsonella and Arsenophonus atpA primers were designed for the other two groups of Cardiaspina species (Additional file 2). The primers were designed from consensus sequences derived from whole genome shotgun sequencing, described in the previous section. There was no indication of multiple genome copies or haplotype diversity in these genes. Surprisingly, however, no contig matching the Arsenophonus atpA gene was found in the C. albitextura whole genome sequence dataset, although Carsonella atp $A$ and host $E F 1 \alpha$ genes were both detected with high similarity to C. densitexta, C. tenuitela and GB Cardiaspina. The $C$. albitextura samples were still subject to qPCR with the Arsenophonus primers, but no amplification was detected, so for C. albitextura, only host EF1 $\alpha$ and Carsonella titres were compared. Primers were designed to amplify products between 97 and 122 bp (Additional file 2).

Efficiency of the primers was tested on a dilution series of genomic DNA extracted from GB Cardiaspina sp., C. fiscella and C. maniformis individuals using the QiaAmp Mini DNA kit (Qiagen). Each template was serially diluted five times (one in 10 dilution) prior to qPCR, to generate primer efficiency curves using Rotor-gene 6000 software (version 2.2.3) (Additional file 4). The $\mathrm{qPCR}$ analysis was performed using the 
Delta Cq (quantification cycle) model without efficiency correction [55] because the efficiency values were within the acceptable range (0.99-1.07).

All primer efficiency tests and experimental qPCR reactions were assembled in duplicate in 100-well rotor discs using a CAS-1200 pipetting robot (Corbett Research). Reaction mix and thermal cycling profile are described in Additional file 2. The melt curve was examined to detect non-target-specific amplicons (none was found) and to ensure little or no primer-dimers were formed. Reference and target gene $\mathrm{Cq}$ values were calculated from the arithmetic average of the technical replicate $\mathrm{Cq}$ values at the same threshold level. Relative symbiont titre was calculated following normalisation to the host EF1 $\alpha$ gene copy number using $2^{-\Delta \mathrm{Cq}}$ [55]. ANOVA and Tukey's HSD test were performed using the multcomp package [56] in $\mathrm{R}$ [57].

\section{S rRNA gene phylogeny}

A DNA sequence alignment was produced from 123 sequences derived from amplicon sequencing, whole genome shotgun sequencing and reference sequences downloaded from GenBank. The 56 representative sequences that were selected from the QIIME amplicon sequencing pipeline for the alignment were between 402 and $433 \mathrm{bp}$ in length and included the 50 most abundant sequences plus six Carsonella sequences that were detected, but at lower relative abundance due to primer mismatches. Two extra Carsonella sequences were extracted from WGS datasets for C. maniformis and $P$. sterculiae (430 bp each), as these sequences were not in the representative set of OTUs. Full-length or near fulllength 16S rRNA gene sequences of eight $\mathrm{S}$-endosymbionts were extracted from the WGS datasets of $C$. albitextura, $C$. densitexta, C. fiscella, C. maniformis, C. tenuitela, GB Cardiaspina sp. (1534-1536 bp) and P. sterculiae (two Sendsymbiont sequences 1489 and 1529 bp). Finally, 57 near full-length reference sequences from GenBank were chosen, many of which were published as Pand S-endosymbionts of psyllids, whitefly, aphids and other Hemiptera [10, 17, 24, 25, 31, 58-65].

Sequences were aligned using pynast against the core set of $16 \mathrm{~S}$ rRNA gene reference sequences within the QIIME pipeline. Partial sequences were included in all phylogenies and coded as missing data ('?'). The evolutionary model was selected using Bayesian information criterion in MEGA 6.06 [66]. Phylogenetic relationships were estimated using Bayesian inference implemented in MrBayes 3.2.2 [67]. Posterior probabilities were calculated using four independent chains, including one cold, for 20 million generations, sampling every 100 generations, or until convergence was reached $(<0.01)$. The first $25 \%$ of trees generated were discarded, and a $50 \%$ majority rule consensus tree was returned. FigTree 1.4.0 [68] was used to view the trees.

\section{Results}

\section{Psyllid samples}

Of the specimens initially selected for this study, 93 were nymphs, but nine were eliminated from the study due to parasitisation by parasitoids, detected by amplification and sequencing of the COI gene (Additional file 3), and a further 15 failed the 16S rRNA gene amplicon sequencing. Adult specimens were also COI or cytb barcoded to help the taxonomic grouping of specimens and as reference for future studies. In total, $142 \mathrm{COI}$ sequences and 64 cytb sequences were submitted to GenBank (Additional file 1).

\section{Psyllid microbiota analysis using $16 \mathrm{~S}$ rRNA gene amplicon sequencing}

A total of 191 individuals from 11 genera, comprising 20 taxa identified to species level and five taxa classified as two Glycaspis spp., two Creiis spp. and GB Cardiaspina sp., were subject to $16 \mathrm{~S}$ rRNA gene amplicon sequencing and generated a total of 7,076,907 paired-end reads. Following trimming, joining of paired ends and quality filtering of the merged sequence at a phred threshold of $>19$, sequences were clustered into OTUs at $97 \%$ identity and OTUs comprising two or fewer reads were removed. For the remaining OTUs, seven chimeras were identified, but for six psyllid taxa, an excessive proportion of sequences were marked for removal by QIIME due to the identification of a single chimeric OTU common to most or all individuals in each species: for Aacanthocnema dobsoni, OTU56 constituting 39-99\% of sequence reads obtained from all individual psyllids of this species; for Creiis sp., two OTU112 constituting 98.1-98.5\%; for Pauropsylla depressa, OTU53 constituting 26-97\%; for Eucalyptolyma maideni, OTU62 constituting 30.4-98.6\%; and for Glycaspis sp., two OTU38 constituting 38.9-98.7\%. One OTU identified as chimeric was found in two out of three individuals of Glycaspis brimblecombei from EucFACE, Richmond, but it constituted 93.4 and $95.3 \%$ of sequence reads in those individuals. However, these sequences that were flagged as chimeric had NCBI BLAST search hits and aligned (with mismatches) over the full sequence length with published insect endosymbiont $16 \mathrm{~S}$ rRNA gene sequences. Therefore, we interpreted these OTUs as true, novel bacterial sequences, primarily because when present in an individual, they were highly abundant and they occurred in multiple individuals of the same species. These OTUs were not eliminated from the analysis, and consequently, over all 191 samples, chimera removal was reduced to a maximum of $0.02 \%$ of reads per library (Additional file 1). After this, the total number of sequence reads per sample ranged from 970 to 151,787 that were clustered into 4410 OTUs. Representative OTU sequence size ranged from 402 to $433 \mathrm{bp}$ (mean \pm std $419.0787 \pm 14.1935$ ). Rarefaction curves of observed OTUs per sample pooled by species were generated (Additional 
file 5) and revealed that read coverage was nearly complete. The Good's coverage metric indicated normalisation of read number to 970 was sufficient for most samples (Good's coverage $>97.1 \%$, mean $99.2 \%$ for samples; Additional file 6) and approached saturation at species level (Good's coverage $>98.3 \%$, mean $99.1 \%$ for species). Based on rarefaction to 970 sequences per sample (i.e. the sequence read number of the library with the overall lowest read number), collectively, 1005 OTUs remained, including 729 OTUs that were now only represented by a single read in the entire rarefied dataset (Additional file 7). Alpha diversity metrics showed low species richness with two to 39 detected OTUs (Additional file 6), with no individual psyllid containing more than five OTUs at more than $1 \%$ relative abundance.

\section{Verification of diversity within bacterial clades}

Several individuals contained multiple sequence clusters (OTUs) of the same bacterial clade, with one dominant OTU ('major' OTU) and one or more minor OTUs present at low relative abundance: this may indicate (1) sequencing error, (2) bioinformatics artefact, (3) multiple $16 \mathrm{~S}$ rRNA gene copies within individual bacterial genomes where the minor OTU represents the less efficient amplification of a multicopy $16 \mathrm{~S}$ rRNA gene, or (4) polymorphic bacterial strains. For instance, Arsenophonus OTU563559 was the most abundant group of clustered sequences in 85 of the 191 samples (up to $96 \%$ of reads), and in those samples consistently co-occurred with a second Arsenophonus OTU86606 (up to 5\% relative abundance), for which the representative sequence differed by five nucleotides (representing higher identity than the elected $97 \%$ clustering cut-off). To validate the OTUs, whole genome sequencing data for the five Cardiaspina spp. that harboured Arsenophonus were assessed and produced consensus sequences that were somewhat intermediate: they aligned with the major OTU at three SNPs, and the minor OTU at two SNPs, suggesting that some OTU SNPs in the 16S rRNA gene amplicon sequencing set were sequencing errors. Examination of the WGS read mappings at various stringencies for all Cardiaspina spp. confirmed the presence of a single isolate with a single $16 \mathrm{~S}$ rRNA gene sequence variant without any haplotype diversity for three of the five species (C. tenuitela, C. albitextura and C. fiscella). However, two species, GB Cardiaspina and C. densitexta, which are phylogenetically very close to each other (but different to the other Cardiaspina species), had an additional four identical SNPs across the 427-bp region of the $16 \mathrm{~S}$ rRNA gene. Read mapping validated both this sequence, and the sequence found in the other three species. Only a single Arsenophonus contig was produced by the genome assembly algorithm; this was demonstrated by a close BLAST match to the $16 \mathrm{~S}$ rRNA gene of 'Candidatus Arsenophonus nilaparvatae', while the next closest matching contig from the assemblies was a single Carsonella contig at lower sequence identity. This corroborates the assertion that there is no intraspecies diversity of bacteria within individuals and species and similarly reduces the possibility that these Arsenophonus genomes contain more than one $16 \mathrm{~S}$ rRNA gene sequence variant.

While it is likely that the picking of Arsenophonus OTU86606 by QIIME is an analysis artefact in the Cardiaspina amplicon libraries (as a consequence of clustering), it was nevertheless found at a relative abundance of $35 \%$ in all three Schedotrioza serrata individuals in the absence of other Arsenophonus OTUs, and this suggests that the OTU represents a valid endosymbiont of this psyllid species.

\section{Identity of P- and S-endosymbionts belonging to the Gammaproteobacteria}

Most psyllid species had a single dominant (>80\%) S-endosymbiont of the Gammaproteobacteria that was found in all individuals of the same species (Table 3, Fig. 2). Arsenophonus and Sodalis (or Sodalis-like) OTUs were common, with representatives of these bacteria found in nine and five psyllid taxa, respectively, including one species that harboured both. Twelve psyllid species were associated with symbionts unique to their lineage that were identified and classified as endosymbionts of the Enterobacteriaceae family, but it was not possible to confidently place them in any described endosymbiont genus due to the short $16 \mathrm{~S}$ rRNA gene amplicon or the lack of reference endosymbiont genomes (Fig. 3, Additional file 8). All G. brimblecombei individuals also harboured an additional symbiont, a Rickettsiella-like OTU (Gammaproteobacteria, Legionellales, Coxiellaceae), at a relative abundance of up to $25 \%$. A fixed Sendosymbiont OTU was found in all populations of a species for all but G. brimblecombei and C. eucalypti (see the following sections); however, screening included as few as three (up to 19) individuals from each species, and a future wider sampling effort is needed to confirm that these Sendosymbionts are fixed in all populations of a species.

In addition, 17 OTUs were classified as Carsonella, the obligate P-endosymbiont of psyllids. Carsonella sequence reads in individuals ranged between 0 and $29 \%$. There were 10 samples that did not produce any Carsonella reads in the full dataset: all six $P$. sterculiae, two $C$. fiscella and two $C$. maniformis individuals. The $C$. fiscella and $C$. manifomis were included in the qPCR experiment, and the presence of Carsonella was confirmed in each individual in high but varying titres (see the 'qPCR' section); $P$. sterculiae individuals are known to harbour Carsonella [3] but were also subjected to Carsonella-specific PCR which confirmed the presence of Carsonella in all individuals. 
Table 3 Bacteria identified by 165 rRNA gene amplicon sequencing

\begin{tabular}{|c|c|c|c|c|}
\hline Species name & P-endosymbiont & Potential S-endosymbiont(s) & $\begin{array}{l}\text { Facultative endosymbionts } \\
\text { (potential reproductive } \\
\text { manipulators) }\end{array}$ & $\begin{array}{l}\text { Potentially transient or } \\
\text { pathogenic bacteria }\end{array}$ \\
\hline \multirow[t]{2}{*}{ Class } & $\begin{array}{l}\text { Gammaproteobacteria } \\
\text { (Halomonadaceae) }\end{array}$ & $\begin{array}{l}\text { Gammaproteobacteria } \\
\text { (Enterobacteriaceae } \\
+ \text { Coxiellaceae) }\end{array}$ & $\begin{array}{l}\text { Alphaproteobacteria } \\
+ \text { Tenericutes }\left({ }^{*}\right)\end{array}$ & $\begin{array}{l}\text { Gammaproteobacteria } \\
+ \text { Tenericutes }\left(^{*}\right) \\
+ \text { Firmicutes }(\#)\end{array}$ \\
\hline & & $\begin{array}{l}\text { Arsenophonus } \\
\text { (>95\% BLAST match to } \\
\text { NCBI Ref_genomes) }\end{array}$ & & \\
\hline Cardiaspina albitextura & Carsonella & $\begin{array}{l}\text { OTU563559 (AN =99\%; } \\
\text { full-length AN =99\%) }\end{array}$ & & \\
\hline Cardiaspina densitexta & Carsonella & $\begin{array}{l}\text { OTU563559 (AN =99\%; } \\
\text { full-length AN =99\%) }\end{array}$ & & \\
\hline Cardiaspina fiscella & Carsonella & $\begin{array}{l}\text { OTU563559 (AN =99\%; } \\
\text { full-length AN =99\%) }\end{array}$ & $\begin{array}{l}\text { Wolbachia (1/12), } \\
\text { Rickettsia }(2 / 12)\end{array}$ & \\
\hline Cardiaspina retator & Carsonella & OTU563559 (AN = 99\%) & & \\
\hline Cardiaspina tenuitela & Carsonella & $\begin{array}{l}\text { OTU563559 (AN =99\%; } \\
\text { full-length AN =99\%) }\end{array}$ & & Escherichia (1/4) \\
\hline Cardiaspina vittaformis & Carsonella & OTU563559 (AN = 99\%) & & \\
\hline GB Cardiaspina sp. & Carsonella & $\begin{array}{l}\text { OTU563559 (AN =99\%; } \\
\text { full-length AN =99\%) }\end{array}$ & Rickettsia (1/14) & \\
\hline \multirow[t]{2}{*}{ Trioza eugeniae } & Carsonella & OTU16 (AN = 97\%) & & $\begin{array}{l}\text { Serratia }(1 / 6) \\
\text { Pseudomonas }(1 / 6)\end{array}$ \\
\hline & & $\begin{array}{l}\text { Sodalis and Sodalis-like } \\
\text { (>95\% BLAST match to NCBI } \\
\text { Ref_genomes) }\end{array}$ & & \\
\hline Cardiaspina maniformis & Carsonella & $\begin{array}{l}\text { OTU86 (SP = 96\%; full-length } \\
\text { SP }=97 \%)\end{array}$ & Lariskella (7/7) & \\
\hline Ctenarytaina bipartita & Carsonella & OTU106 (SP = 96\%) & & \\
\hline Ctenarytaina spatulata & Carsonella & OTU24 (SG = 96\%) & & \\
\hline \multirow[t]{2}{*}{ Glycaspis sp. 2} & Carsonella & OTU38 (SG = 95\%) & Wolbachia (1/8) & \\
\hline & & $\begin{array}{l}\text { Unclassified } \\
\text { Enterobacteriaceae }\end{array}$ & & \\
\hline Creiis sp. 1 & Carsonella & OTU103 (SG = 93\%) & Lariskella (3/3) & \\
\hline Creiis sp. 2 & Carsonella & OTU112 (BP = 90\%) & & \\
\hline Eucalyptolyma maideni & Carsonella & OTU62 (ME = 93\%) & Wolbachia (4/9) & \\
\hline Glycaspis sp. 1 & Carsonella & $\begin{array}{l}\text { OTU37 }(M E=91 \%)+\text { OTU13 } \\
(M E=92 \%)\end{array}$ & & \\
\hline Acizzia solanicola & Carsonella & OTU120 (CE = 92\%) & & \\
\hline Aacanthocnema dobsoni & Carsonella & OTU56 (WG = 87\%) & Rickettsia (1/4) & Phytoplasma $(2 / 4)^{*}$ \\
\hline Pauropsylla depressa & Carsonella & OTU53 (ME = 92\%) & & $\begin{array}{l}\text { Erwinia }(2 / 7), \text { Pseudomonas } \\
(2 / 7), \text { Enterobacter }(1 / 7)\end{array}$ \\
\hline \multirow[t]{2}{*}{ Trioza magnoliae } & Carsonella & OTU9965 (BA = 89\%) & Wolbachia (3/3) & \\
\hline & & Multiple S-endosymbionts & & \\
\hline Creiis corniculata & Carsonella & $\begin{array}{l}\text { OTU563559 (Arsenophonus } \\
\text { AN }=99 \%)+ \text { OTU23 }(C E=93 \%)\end{array}$ & Rickettsia (1/6) & \\
\hline Protyora sterculiae & Carsonella & $\begin{array}{l}\text { OTU28 (Schneideria-like CE }=92 \% \text {; } \\
\text { full-length CE }=90 \%)+ \text { OTU46 } \\
(\text { Schneideria-like BP }=91 \% \text {; } \\
\text { full-length BP }=91 \%)\end{array}$ & & \\
\hline Schedotrioza serrata & Carsonella & $\begin{array}{l}\text { OTU96731 (Sodalis SP }=99 \%)+ \\
\text { OTU86606 (Arsenophonus AN }=99 \%)\end{array}$ & & \\
\hline
\end{tabular}


Table 3 Bacteria identified by 16S rRNA gene amplicon sequencing (Continued)

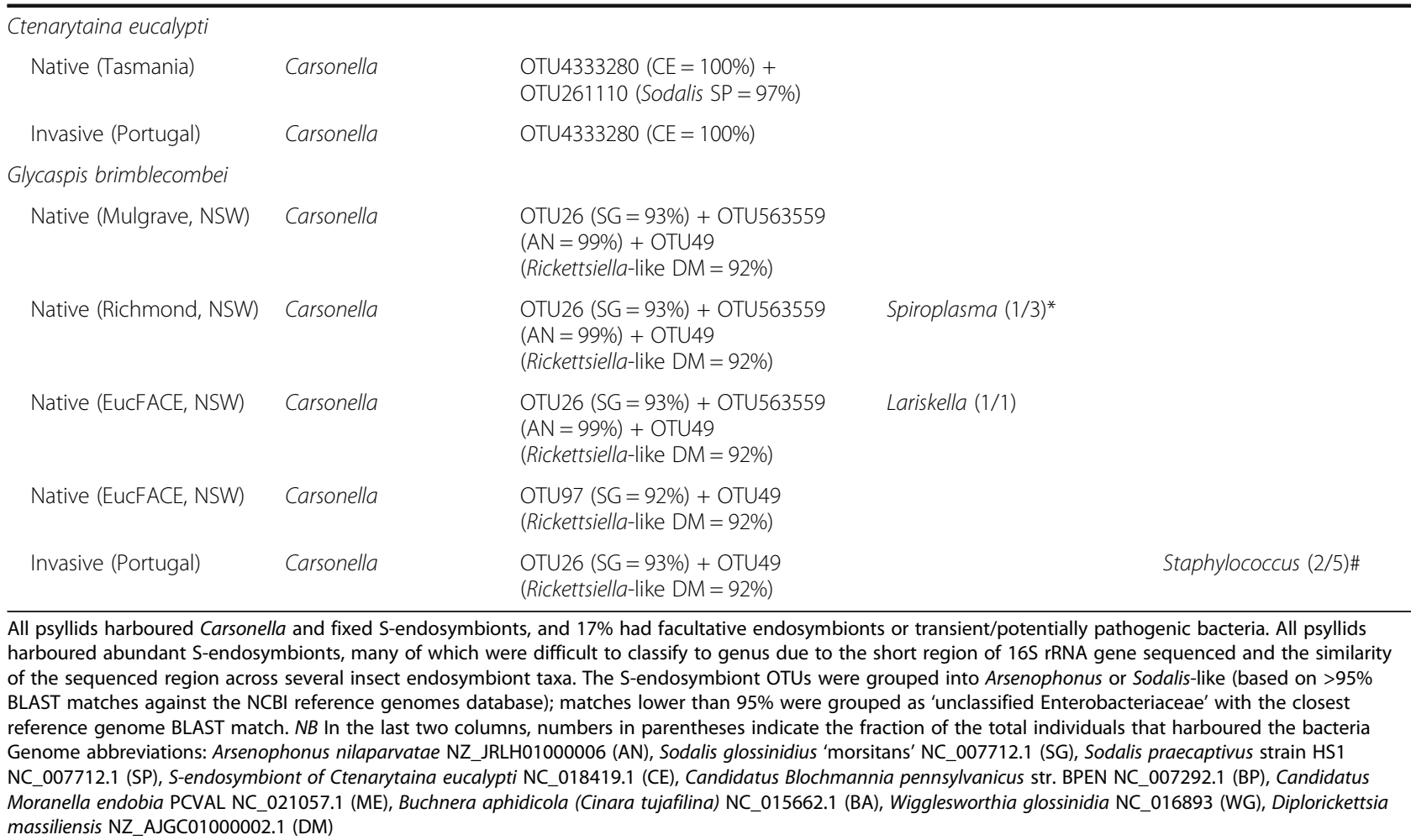

\section{Relative quantification of $\mathrm{P}$ - and S-endosymbiont titres by qPCR}

According to qPCR, Carsonella was much more abundant than the 16S rRNA gene amplicon sequencing analysis suggested (Additional file 9; Fig. 4). Most individuals had higher titres for Carsonella than Arsenophonus (21 out of 30 individuals, 1.1- to 383-fold higher titre), and Carsonella titre was 16- to 261-fold higher than Sodalis in the seven $C$. maniformis individuals. Carsonella was relatively more abundant than host cells (in 32 out of 42 individuals), notwithstanding the extraction of DNA was from whole psyllids, and Carsonella is restricted to the abdominal bacteriome. The titre of Carsonella in C. fiscella samples 124 and 125 was five- to eightfold higher than host cells, and 19- to 22-fold higher than Arsenophonus, contrary to the absence of Carsonella reads in the MiSeq amplicon dataset. Carsonella was on average 53 times higher than $C$. maniformis host cells, and while Sodalis was detected at much lower titres $(0.1$ to $2.5 \times$ relative to host cells), it was in the same range as Arsenophonus in the other Cardiaspina species.

The titre of the endosymbionts was highly variable across individuals of the same species (Fig. 4) and did not vary according to developmental stage or sex (chi-square test $\mathrm{df}=2, p=0.333$ ). Carsonella titre in C. maniformis was significantly higher than the Carsonella titre in all other Cardiaspina spp. and may correlate to the association with Sodalis in C. maniformis (Fig. 4).
Furthermore, the primer development for the qPCR assay revealed that the Arsenophonous S-endosymbiont of C. albitextura lacked atpA which confirmed Arsenophonus strain diversity across the different Cardiaspina species [3] and requires further investigation with regard to the significance of this loss for genome function.

\section{Co-occurrence of multiple S-endosymbiont genera in some psyllid species}

The bacterial communities of several psyllid species contained multiple $\mathrm{S}$-endosymbionts at high relative abundance (Table 3, Fig. 5). All S. serrata individuals harboured both Arsenophonus and Sodalis OTUs (10.3\% divergence in 427 bp) and clearly demonstrated coinfection by two distinct bacterial lineages at an average relative abundance of 34 and 59\%, respectively. Similarly, Creiis corniculata possessed Arsenophonus (68\% of reads) and a distinct Enterobacteriaceae OTU (16\% of reads) with a $12.9 \%$ divergence in their $16 \mathrm{~S}$ rRNA gene sequence. In P. sterculiae, two distinct S-endosymbionts (9.6\% divergence) classified to Enterobacteriaceae were detected, and these OTUs were present in each individual at an average of approximately 82 and $16 \%$ relative abundance. The presence of these diverged sequences in P. sterculiae was corroborated by the WGS dataset: both sequences were detected by mapping reads to the two OTU sequences at high stringency, and the differential abundance based on sequence coverage (ratio 49:1) in the WGS dataset 


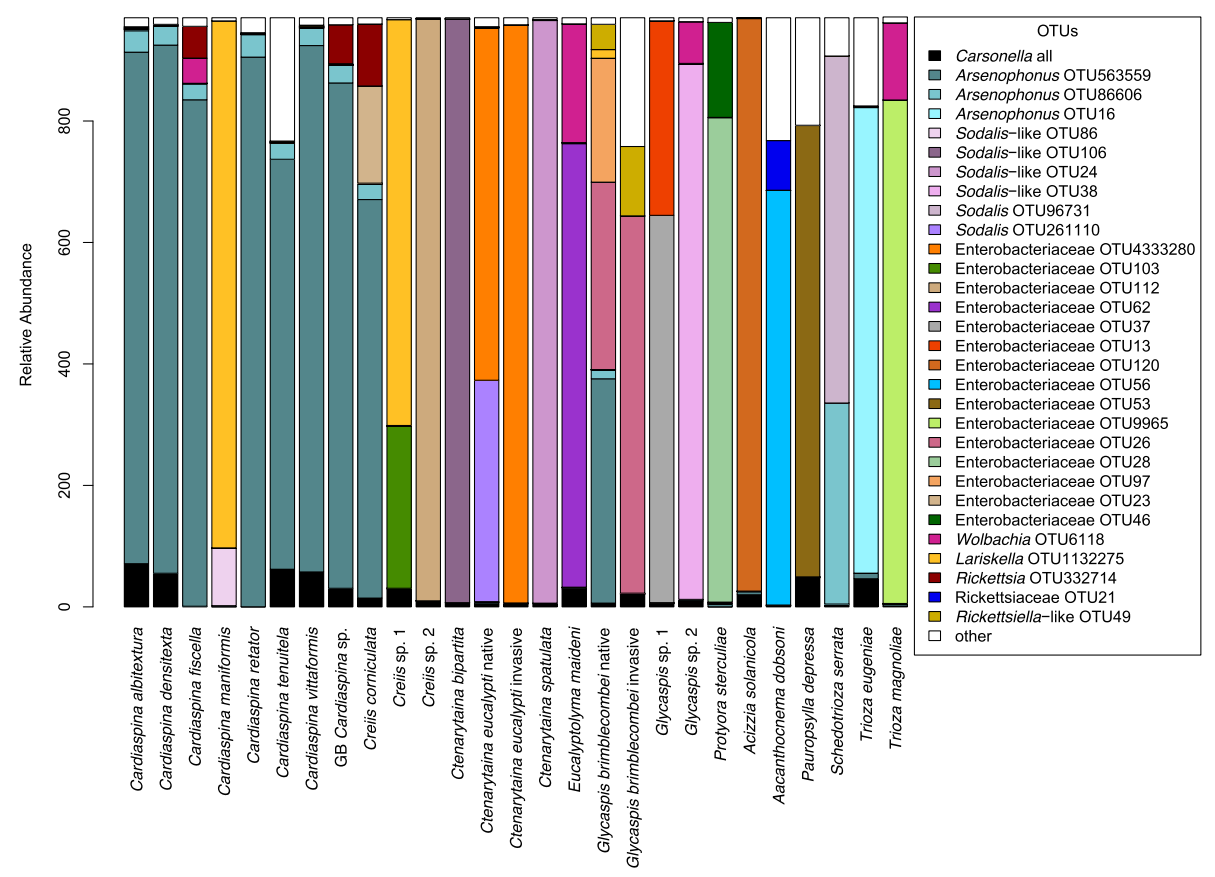

Fig. 2 Microbial composition of the dominant OTUs detected in 191 individuals of 25 psyllid species (summarised by species). Carsonella (P-endosymbiont), various S-endosymbionts and potential reproductive manipulators were included; others including transient or pathogenic OTUs were grouped into 'other'. Glycaspis brimblecombei and Ctenarytaina eucalypti were split into native and invasive samples because for these two species individuals from both native and invasive ranges were available

demonstrated that these were not multiple intra-genomic $16 \mathrm{~S}$ rRNA gene copies. Hence, two independent methods validated the presence of two distinct Enterobacteriaceae S-endosymbionts in P. sterculiae, one at high and one at low titre.

In Glycaspis sp. 1, two Enterobacteriaceae OTUs were detected in each individual but they differed by only $3 \%$ and may therefore be haplotypes of a single bacterial species that had diverged after acquisition by the host insect, as opposed to different bacterial lineages that had been independently acquired (such as seen in P. sterculiae).

Low count reads need to be treated with caution; however, our detection of bacterial lineages at low relative abundance in all individuals of some but not all host species (therefore potential fixation in some species) needs noting. Although T. eugeniae possessed a distinct Arsenophonus sequence, each individual also harboured low levels (mean proportion of $0.9 \%$ ) of the dominant Arsenophonus found in most individuals of the Cardiaspina genus. Each individual of P. sterculiae, Acizzia solanicola and Trioza magnoliae also harboured low levels of this Arsenophonus sequence (mean proportion of $0.3-0.5 \%$ ), and this is in the absence of a relatively abundant Arsenophonus OTU dominating the bacterial community in each of these species. However, Arsenophonus sequences were not detected in the P. sterculiae WGS data set.

Specimens of G. brimblecombei were collected from both the native Australian range and from Portugal where it is invasive. All individuals had a Rickettsiellalike bacterium. In G. brimblecombei from Australia, six out of nine individuals also carried both Arsenophonus and OTU26, a currently unclassified Enterobacteriaceae S-endosymbiont (13.1\% divergence separating the two Sendosymbionts). The remaining three specimens carried a single Enterobacteriaceae endosymbiont-the common OTU26 in one and a related OTU97 (3.4\% diverged) in the other two individuals. In the Portuguese samples, only the common OTU26 endosymbiont was found. Similar differences in invasive versus native populations were detected in C. eucalypti, where the previously published S-endosymbiont of C. eucalypti [10] co-occurred with a less abundant Sodalis-like bacterium (that was differentiated by $4.7 \%$ nucleotide diversity) in all specimens from the native Australian range, but only the more abundant endosymbiont was detected in the Portuguese samples. For all other species examined in this study, all replicated populations (from one to seven populations per species) harboured fixed S-endosymbionts.

\section{Endosymbionts belonging to the Alphaproteobacteria and other bacterial classes}

Alphaproteobacterial 16S rRNA gene sequences were found in psyllids that were not dominated by Gammaproteobacteria (but still contained Gammaproteobacteria as S-endosymbionts). The OTUs included Wolbachia (Rickettsiales, Alphaproteobacteria) which was detected at 


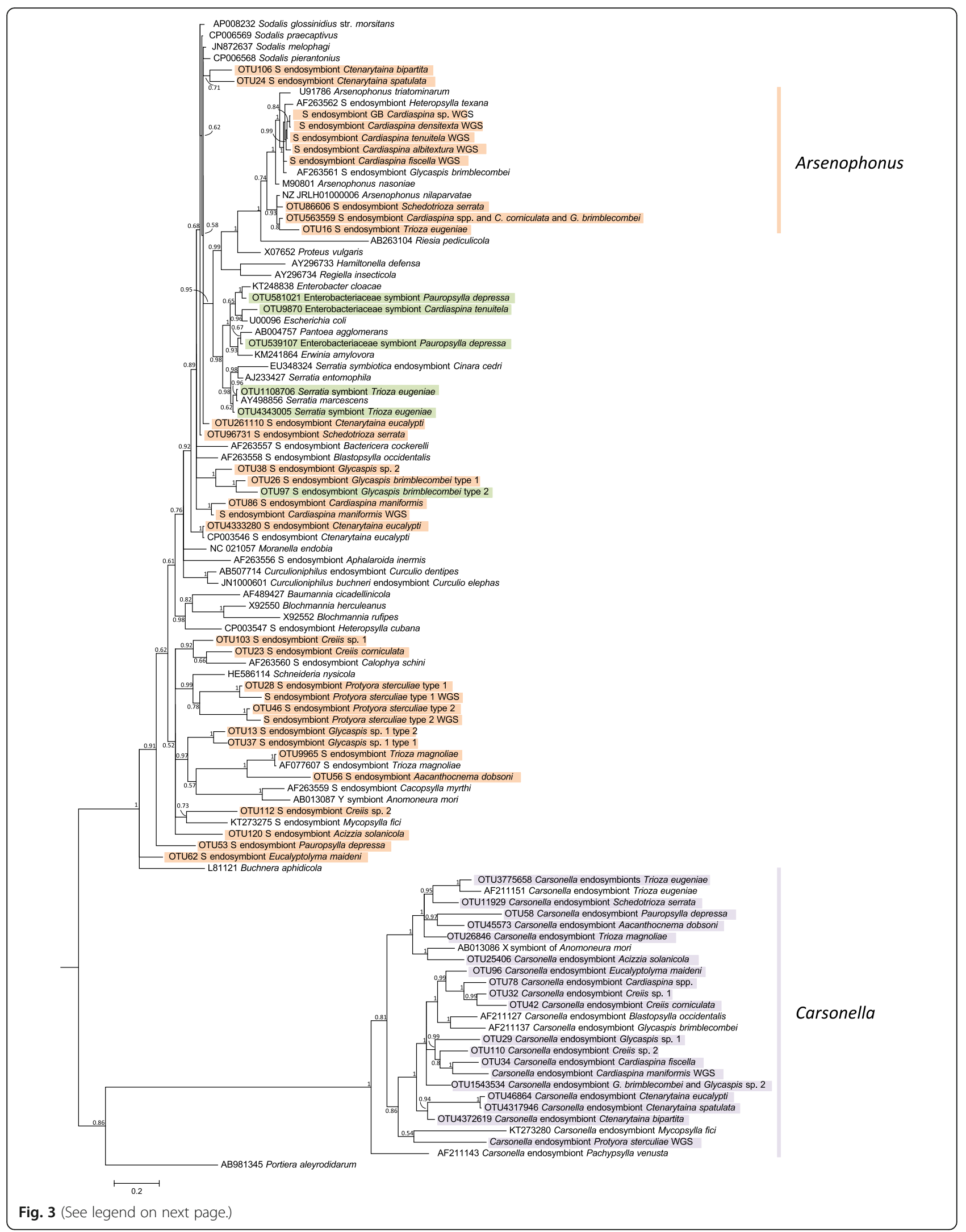


(See figure on previous page.)

Fig. 3 Bayesian phylogenetic tree of $16 \mathrm{~S}$ rRNA gene sequences, including those acquired from amplicon sequencing of individuals from 25 psyllid species. This tree displays Gammaproteobacteria from the families Halomonadaceae (Carsonella sequences from this study highlighted in purple) and Enterobacteriaceae which includes the S-endosymbionts that were found in all individuals of a species (or in all individuals of the native range for C. eucalypti or G. brimblecombei) highlighted in orange, or not fixed within a species highlighted in green. Posterior probabilities are displayed at the node when $>50 \%$. Scale bar shows nucleotide substitutions per site. The complete phylogenetic tree with all $16 \mathrm{~S}$ rRNA gene sequences of this study (including other Gamma- and Alphaproteobacteria) is shown in Additional file 8

high relative abundance (11-66\%) in some individuals of $C$. fiscella, E. maideni and Glycaspis sp. 2 and in all T. magnoliae, as well as at very low relative abundance below $1 \%$ and low prevalence in 14 individuals of nine species (Additional file 7). Two Rickettsia (Rickettsiales) OTUs that displayed 96.8 and $99.3 \%$ identity to the Rickettsia endosymbiont of the pea aphid (GenBank KP710438) were at high relative abundance in one of the four $A$. dobsoni individuals (OTU21), one of the six C. corniculata, one of the $14 \mathrm{~GB}$ Cardiaspina sp. and two of the 12 C. fiscella (OTU332714). Lariskella (Rickettsiales) was dominant and fixed in Creiis sp. 1 and C. maniformis. Spiroplasma (Tenericutes) was detected in a single $G$. brimblecombei individual, but at a modest $2.8 \%$ relative abundance. The Alphaproteobacteria at high relative abundance always co-occurred with gammaproteobacterial S-endosymbionts in all of these psyllids, albeit with the gammaproteobacterial S-endosymbiont at a lower relative abundance in each individual (Fig. 5).

\section{Transient bacteria and potential plant pathogens}

High relative abundance of Phytoplasma sp. was detected in two out of the four A. dobsoni individuals (20 and $59 \%$ of reads) collected from Allocasuarina verticillata; these were isolates with $99 \%$ similarity to a Phytoplasma found in Allocassuarina muelleriana [69], where it causes yellowing of the foliage. 'Candidatus Liberibacter spp.', causal agents of plant diseases including Huanglongbing in citrus and zebra chip disease in potatoes are vectored by psyllids. However, no Liberibacter was detected in any of the samples examined here. Other bacteria that were detected in some psyllid individuals at high relative abundance included OTUs that were similar to Erwinia and Pseudomonas.

\section{Bacterial community diversity}

Psyllid bacterial communities were generally low in species richness and dominated by few relatively abundant species (Additional files 6 and 7). Based on the rarefaction analysis, for the number of OTUs (observed_species) detected in each psyllid species, it appeared that the mean number of OTUs found in the gall-forming S. serrata was highest and more than twice as high as in any other psyllid species (Additional file 5). Furthermore, the next psyllid species that were ranked highest with regard to the number of OTUs included the other three triozid gall-forming species (T. eugeniae, T. magnoliae and P. depressa) and the flush-feeder G. brimblecombei, however, there was no overall statistical support for this.

Comparison of the alpha diversity metrics Shannon, Simpson and the number of observed species (compare_alpha_diversity.py) using non-parametric statistics showed that free-living psyllids harboured the least diverse bacterial communities compared to lerp builders and gall formers. Both lerp $(t$-stat $=3.23, p=0.012)$ - and gall formers $(t$-stat $=3.02, p=0.012)$ had significantly higher Shannon diversity than free-living psyllids, and gall-forming psyllids were significantly higher than free-living psyllids for the Simpson metric $(t$-stat $=2.36$, $p=0.063)$. Senescence feeders had higher Shannon diversity $(t$-stat $=2.98, p=0.018)$ and observed species $(t$-stat $=4.55, p=0.003)$ than flush feeders, but no difference in the Simpson metric. There were no significant differences in Shannon, Simpson or observed species metrics when samples were grouped by genus or species. Too few males were sampled for statistical rigour, but a comparison of nymphs versus adult females for species with adequate sampling (i.e. C. albitextura, $C$. fiscella, $P$. depressa and $P$. sterculiae) also returned no significant difference for any alpha diversity metric. These results seemed to be driven by the higher incidence of facultative Alphaproteobacteria (e.g. Wolbachia, Rickettsia, Lariskella) and transient (possibly gut associated) or pathogenic bacteria detected in gall- and lerp-forming psyllids (Table 3 ).

Beta diversity comparisons of weighted and unweighted UniFrac and Bray-Curtis dissimilarity metrics showed significant differences when categorised at all levels: species, genus, niche, feeding type and host plant (Additional file 10). However, species identity governed the minimal microbial composition (Fig. 5), and the unweighted UniFrac PCoA plot (Fig. 6) displayed the loose clustering of the lerp-forming species (mostly Cardiaspina, Glycaspis and Creiis species harbouring genetically similar Arsenophonus OTUs), as distinct from the loose cluster of free-living and gall-forming species, many of which harboured Sodalis-like OTUs. This clustering was more pronounced in the weighted UniFrac when abundance was included, due to the dominance of the S-endosymbiont read count. The Bray-Curtis PCoA plot contrasted with UniFrac to differentiate the OTUs as separate entities irrespective of phylogenetic 


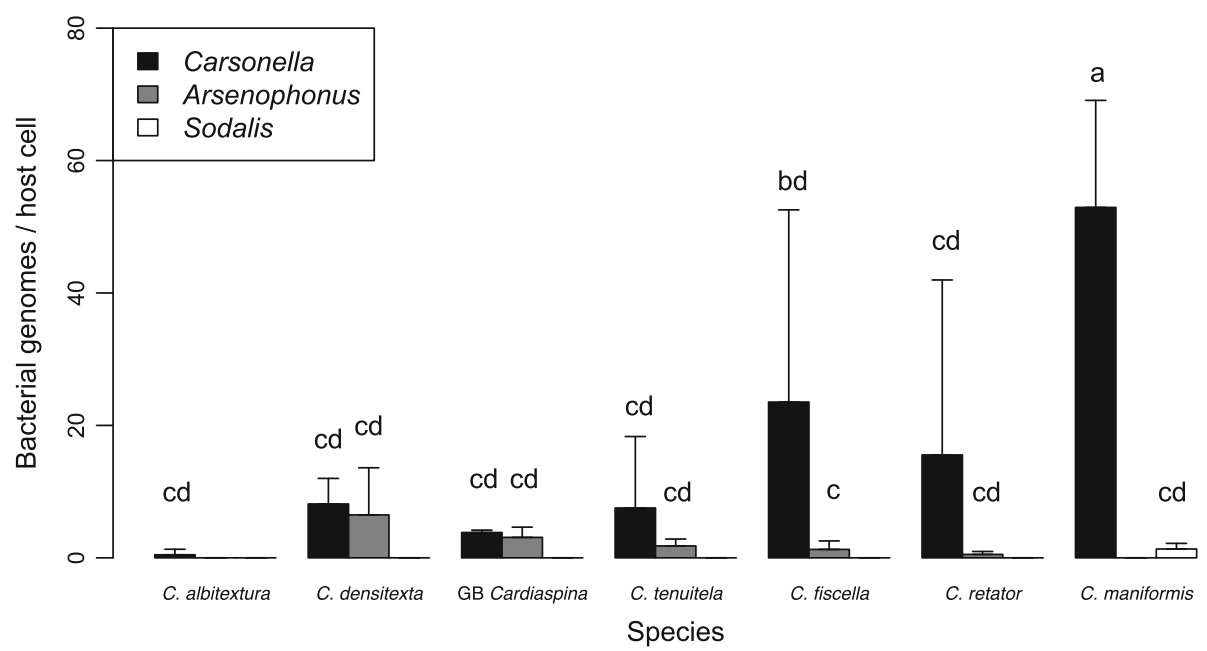

Fig. 4 Relative titres of P-and S-endosymbionts in Cardiaspina spp. determined by qPCR. Cq values for Carsonella, Arsenophonus and Sodalis were normalised to the EF1a host gene (see Additional file 8), and species means of endosymbiont copy number were plotted. Tukey's post hoc tests were performed and the results displayed over each bar, demonstrating no significant difference between the titres of the P-and S-endosymbionts within and between four species, but significantly higher Carsonella titres for C. fiscella and C. maniformis than the other species. Cardiaspina albitextura was included to display relative Carsonella titre only; while Arsenophonus was present in each individual of $C$. albitextura based on amplicon sequencing data, it was not detected using the atpA qPCR primer set

similarity, hence the tight clustering of the multiple Cardiaspina species which carried the same single dominant OTU and the spread of species that either (1) carried relatively abundant facultative endosymbionts, (2) harboured relatively abundant transient or opportunistic bacteria or (3) harboured multiple Sendosymbionts at high relative abundance (Fig. 6).

\section{Discussion}

We analysed the complete bacterial diversity and community composition of 191 individuals of 25 diverse psyllid species, including seven species for which bacterial associates were characterised for the first time. This is the most comprehensive analysis of psyllid-associated bacterial diversity and composition across species so far, and it revealed for each psyllid species a minimal community of core microbiota consisting of only a few bacteria, including Carsonella as universal P-endosymbiont and at least one S-endosymbiont belonging to Gammaproteobacteria. $\mathrm{P}$ - and S-endosymbionts were found in all individuals of psyllid species, confirming strict maternal inheritance of this minimal bacterial core community. The $16 \mathrm{~S}$ rRNA gene amplicon sequencing analysis detected for most individuals the presence of at least one dominant Enterobacteriaceae S-endosymbiont taxon that was fixed across all tested individuals of host species, and supported the hypothesis that complementation by another endosymbiont may have led to co-dependencies between psyllid Pand S-endosymbionts $[3,17]$. The species identity of this presumably complementing S-endosymbiont varied across host taxa, such that closely related host taxa (e.g. within psyllid genera) had different dominant S-endosymbionts, thereby supporting the hypotheses of host switching and replacement of S-endosymbionts in psyllids. Furthermore, our study of psyllid microbiota provided an unexpectedly rich source of new and undescribed endosymbiont diversity, with unclassified S-endosymbionts (all belonging to Enterobacteriaceae) in 12 of the 25 psyllid species. Interestingly, five psyllid species possessed two or three distinct and highly abundant S-endosymbiont taxa, and this may constitute examples of ongoing endosymbiont complementation or replacement as it is expected to occur based on earlier cophylogenetic analyses that demonstrated host switches for S-endosymbionts of psyllids [3, 17]. For other psyllid species, besides the dominant S-endosymbiont, we detected low-frequency reads of other S-endosymbionts in all individuals and these 'symbionts in waiting' may form the basis of future endosymbiont complementation or replacements.

\section{Psyllids have ubiquitous and novel S-endosymbionts}

The overall low diversity of bacteria found within 25 psyllid species aligns with previous studies of other hemipterans including studies of a number of psyllid species [22, 70]. Dominant bacterial clades found in each psyllid species were related to common insect endosymbionts localised to bacteriomes, including Arsenophonus [26], Sodalis [71], the Enterobacteriaceae S-endosymbiont of $A$. mori [25] and Schneideria, the bacteriome-associated P-endosymbiont of stinkbugs [72]. All Cardiaspina and Ctenarytaina species 




Fig. 5 Heatmap showing relative abundance $>1 \%$ of OTUs labeled to genus or family level in each species. Each row represents a microbial OTU, and colour shading indicates the relative abundance according to the inset legend on the top right. Columns represent each psyllid species (C. eucalypti and G. brimblecombei samples were also divided into specimens of native and invasive populations) and were ordered by Euclidean hierarchical clustering. Class level designations for the microbial OTUs are presented on the left of the figure. Psyllid families are indicated by the coloured bar: Aphalaridae (green), Carsidaridae (blue), Psyllidae (yellow) and Triozidae (orange)

harboured S-endosymbionts classified to either Arsenophonus, Sodalis or Sodalis-like bacteria; however, in several psyllid species, we discovered new bacterial endosymbiont taxa for which there are no genomic references in databases. Many fell into diverse clusters within Enterobacteriaceae that remained phylogenetically unresolved due to the short 16S rRNA gene amplicon used for most species, and future work should involve comprehensive analysis of these undescribed bacteria using full genomes or multilocus characterisation. Also particularly noteworthy is the finding of a Rickettsiella-like bacterium in all G. brimblecombei. Previously a
Rickettsiella-like bacterium has been described from Cecidotrioza sozanica [32], and Rickettsiella has been found to impact body colour of the aphid Acyrthosiphon pisum [73]. This may also play a role in G. brimblecombei which also displayed green/red colour polymorphism (MR, personal observation), and this warrants further investigation.

The potential for abundant S-endosymbionts to evolve to obligate mutualism is supported by bacterial community analysis by UniFrac-based PCoA which demonstrated that psyllid phylogenetic relationships were the most important determining factors in clustering the microbiota. Certain characteristics of obligate bacterial associations 

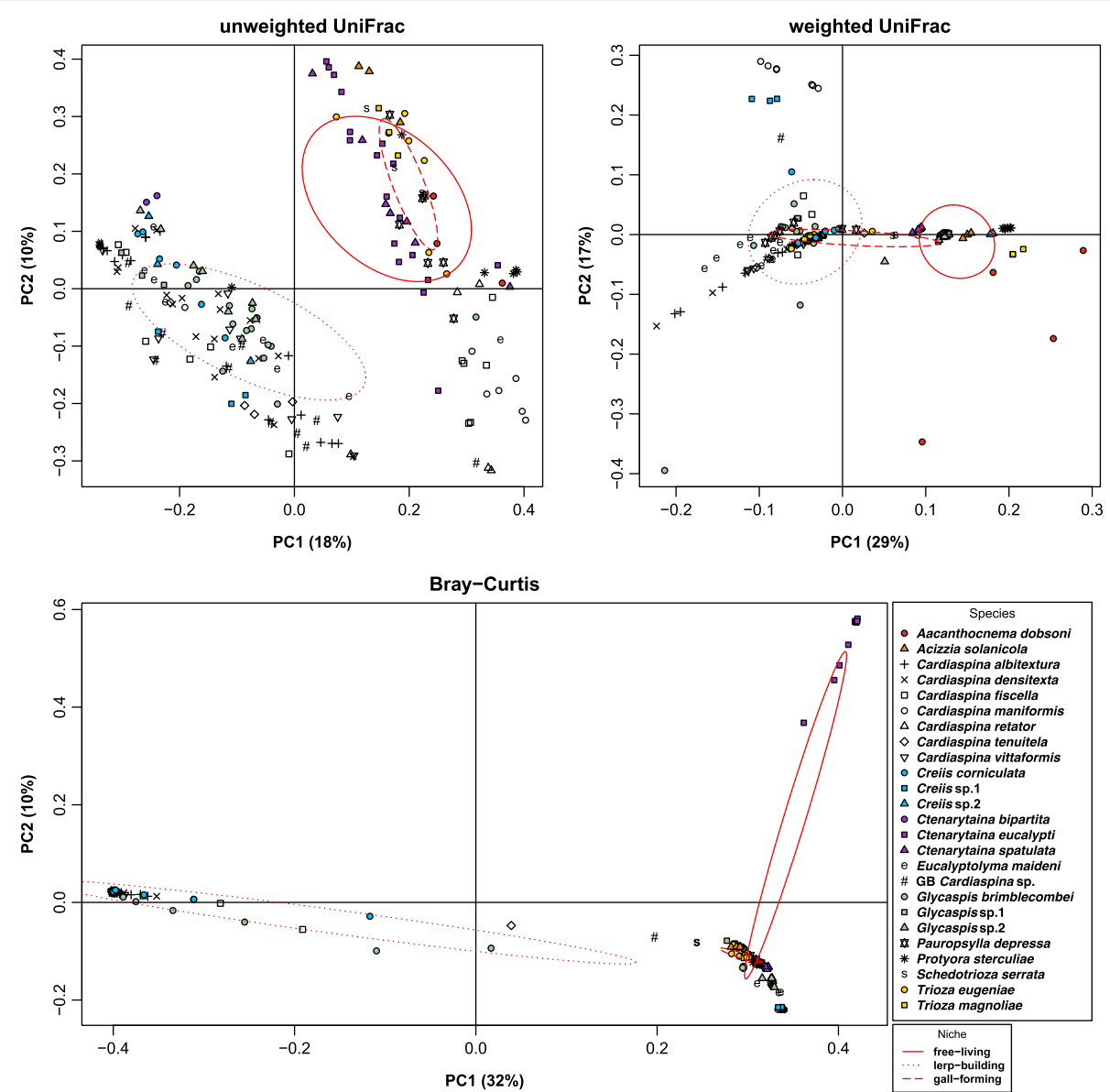

Fig. 6 Principal coordinates analysis (PCOA) of three distance metrics: unweighted UniFrac, weighted UniFrac and Bray-Curtis, based on OTUs calculated at $97 \%$ similarity. Microbial communities of 191 psyllid individuals of 25 species are represented. Axes labels denote the percentage of variation that is contained in each principal coordinate; ellipses represent the standard deviation of the cluster centred on each ecological niche

(such as vertical transmission, high titre, 100\% prevalence in all populations of a species) are strongly supported by the data; however, facultative endosymbionts (those that are not strictly required by the host, e.g. Wolbachia) may also embody these characteristics. Vertical transmission of Arsenophonus in three Cardiaspina species has previously been demonstrated by detection of this endosymbiont within surface-sterilised eggs [3]. At higher taxonomic levels, it has also been found that some but not all species within psyllid genera (or within a family, for example $A$. dobsoni and T. magnoliae of Triozidae) tended to be associated with related isolates of the same S-endosymbiont lineage supporting a combination of repeated host switches into the same host lineage (host tracking) and codivergence $[3,31]$.

\section{Influence of ecological niche and host plant use on microbiota}

It has previously been reported that some gall-forming psyllid species were depauperate of S-endosymbionts and this led to the hypothesis that S-endosymbionts may not be essential to gall-forming psyllids, perhaps due to the more nutrient-rich habitat of galls when compared to lerp and free-living niches [32]. However, we found $100 \%$ presence of gammaproteobacterial S-endosymbionts; Wolbachia was also fixed in T. magnoliae. Alpha diversity metrics also contradicted the hypothesis of depauperate S-endosymbionts in gall formers, with lower diversity found in lerp-forming and free-living psyllids. Bacterial community comparisons across psyllid species with not only different ecological niches but also different feeding habit (flush or senescence) and host plant (eucalypt and non-eucalypt) did not demonstrate a clear effect of any of these factors due to the strong effect of psyllid species on microbial composition. Inclusion of species within a genus that exhibit different characteristics (such as gall-forming species of the Glycaspis subfamily Synglycaspis to contrast with the more common lerp-building species or a larger sampling of a given psyllid species that has multiple host tree associations) will be required to tease out these effects on bacterial composition and diversity. 


\section{Endosymbiont loss in invasive ranges}

A striking difference in S-endosymbiont incidence was found between native Australian and invasive populations of G. brimblecombei and C. eucalypti. In both cases, two relatively abundant $\mathrm{S}$-endosymbionts were detected in the native range, but only a single dominant S-endosymbiont was detected in the invasive samples from Portugal. This is also confirmed by a previous report for G. brimblecombei in California where only Arsenophonus and no other endosymbiont was found [17], at an overall prevalence of $40 \%$, with variability ranging from 0 to $75 \%$ across Californian populations [5], and whole endosymbiont genome sequencing analysis of invasive C. eucalypti in California has also revealed the presence of a single S-endosymbiont [10] without the presence of the additional endosymbiont that we found in Australian specimens of this species. Furthermore, D. citri specimens from Florida were bereft of the Arsenophonus strain detected in Asian samples from where this psyllid originates [26, 74]. The examples of G. brimblecombei and C. eucalypti suggest a dynamic endosymbiont community, with the potential loss of microbial diversity in the invasive ranges, with impacts on host insects that may rely on endosymbiont function for nutrition and development. Loss of some but not all endosymbionts has previously been reported for invasive host populations of a thrips (e.g. loss of Wolbachia but not Cardinium in invasive Pezothrips kellyanus), possibly due to incomplete transmission, stochastic effects or selection pressures that vary throughout host ranges [75].

\section{Symbiont replacement}

Previous studies have found Carsonella in all psyllid species [3, 24]. In our study, each psyllid also harboured Carsonella, and qPCR results showed that Carsonella was more abundant than S-endosymbionts in individuals of Cardiaspina, although at extremely variable titres. The dominance of Arsenophonus or Sodalis bacteria in all Cardiaspina individuals and species (although at titres generally lower than Carsonella) also supported the notion that association with S-endosymbionts can be viewed as obligate symbiosis for psyllids. However, some psyllid species typically had multiple S-endosymbionts in all individuals (some at high and others at low relative abundance), and this may be indicative of ongoing endosymbiont complementation or replacement (e.g. [3]). The characterisation of the ecological processes leading to endosymbiont complementation or replacement, particularly in their early stages (i.e. incipient endosymbiont complementation or replacement), will be critical to understanding the evolution of endosymbiosis and the frequency of endosymbiont complementation and replacement across host species. Our multispecies study has demonstrated potentially new endosymbiont combinations within and across related psyllid species, and this will highlight the chronology of changes that may occur in endosymbiont genomes due to selective processes involved in endosymbiont compensation and replacement in insects with minimal bacterial communities. The absence of essential gene pathways due to genomic erosion of long-term obligate endosymbionts, such as seen in Carsonella, means that $\mathrm{S}$-endosymbionts are required to complement their role. This could also lead to Pendosymbiont replacement, exemplified by the loss of Sulcia from some Fulgoroidea (Auchenorrhyncha) lineages [21]; however, a loss of Carsonella has not been observed for any psyllid species. It could also lead to the replacement of one S-endosymbiont of a host species with another, and we have found evidence for this.

We interpret the presence of two or three clades of Sendosymbionts in individuals of psyllid species as a sign of incipient endosymbiont complementation or replacement, which warrants further examination. Multiple Sendosymbionts are common in whitefly, Bemisia tabaci (Hemiptera), and various combinations of the endosymbionts are found in its distinct biotypes (or species) whereby most S-endosymbionts are not fixed within host populations [9]. In S. serrata, Sodalis was more abundant than Arsenophonus in each of the three individuals; however, for $S$. serrata, only one population was sampled, and a more extensive screening of populations will reveal whether this bacterial community is indicative of this psyllid species across its distribution. In addition, whole genome sequencing of Carsonella and the two Sendosymbionts will be useful in assessing the genome characteristics of the endosymbionts and levels of metabolic complementarity. Competition between bacteriomeassociated bacteria may be minimised if located in different bacteriocyte types [76]. In situ localisation of the bacterial cells to the host tissue is needed to reveal whether endosymbionts are either co-localised or compartmentalised, and this will be an essential step to further investigate the interaction dynamics between multiple bacterial species and the host. Other important information will be obtained by the comparative analysis of endosymbiont and host genomes.

Conceptually, symbiont complementation and replacement must begin with the opportunity for horizontal transmission of an endosymbiont into a new host, and this spillover acquisition [2] needs to be followed by establishment of the new endosymbiosis through reliable vertical transmission and host adaptation while some, if not most, of these new host-endosymbiont associations may be lost. The first contact may occur through introgression, interactions with parasitoids, parasites or predators, or via the sharing of a habitat $[77,78]$. Psyllids have a large diversity of specialist parasitoids [50], with COI barcodes of parasitoids also detected in psyllid nymphs of this study, and they may 
play a role in transmission of endosymbionts across psyllid species. Similarly, the genetic relatedness of Wolbachia strains in highly divergent arthropod taxa demonstrates horizontal transmission. For Rickettsia endosymbionts, it has been demonstrated that they can be transmitted between whiteflies via phloem sap during feeding [79]. Some of the psyllid species in our study feed on related, but not identical host plant species, yet host plants could play a role as transmission platform. Based on our experimental design, it is not possible for us to conclude whether host plants play a role in horizontal transmission of psyllid endosymbionts; however, a previous study has not found any Cardiaspina S-endosymbionts in Eucalyptus leaves [3].

\section{Facultative endosymbionts as potential reproductive manipulators}

Wolbachia bacteria are well-studied mostly facultative endosymbionts, which commonly induce reproductive manipulations of their hosts, such as cytoplasmic incompatibility, feminisation or male-killing in diplodiploid hosts [80]. Wolbachia was only found at high prevalence in $T$. magnoliae (3/3 individuals); however, it has also been found at high prevalence in D. citri [26] and is fixed in three Mycopsylla species [31, 81], but it is unknown whether Wolbachia manipulates their host's reproduction in any of these psyllid species. Furthermore, Wolbachia can have fitness benefits for their host under times of nutrient stress [82] and has become an obligate mutualist in its association with bedbugs where it is situated in the bacteriome provisioning its host with B vitamins [83].

Rickettsia is a species of Rickettsiales that has been found frequently in whiteflies [9] and aphids. In aphids, the presence of Rickettsia suppresses the abundance of the P-endosymbiont Buchnera and confers a fitness cost on the host [84]. In our study, two Rickettsia sequences were detected at low prevalence but high titres within individuals: the first in three eucalypt psyllids-C. fiscella, GB Cardiaspina sp. and C. corniculata-and the second in Allocasuarina-associated A. dobsoni. Cardiaspina fiscella was the only species to harbour both Wolbachia and Rickettsia, but these bacteria did not co-occur in the same individual.

Lariskella was found at $100 \%$ prevalence in C. maniformis and Creiis sp. 1, both collected from Eucalyptus tereticornis. This endosymbiont has previously been detected in stinkbugs, fleas and ticks. In stinkbugs, Lariskella co-occurs with the P-endosymbiont Schneideria, in the bacteriome and ovaries, and is vertically transmitted to offspring [85] while in our study, it was found with Sodalis and Enterobacteriaceae Sendosymbionts. Lariskella is also closely related to Wolbachia and Rickettsia, and it has been thought that it manipulates host reproduction [85]. It is not yet known whether any of these Alphaproteobacteria manipulate psyllid reproduction; no sex ratio bias in psyllid populations has been recorded so far [33], and to the best of our knowledge, no reports of cytoplasmic incompatibility exist for psyllids.

\section{Low abundance and prevalence of transient gut bacteria,} potential pathogens and the absence of chloroplast DNA

Only six of 191 specimens carried bacteria other than the previously discussed endosymbionts at greater than $1 \%$ relative abundance, and these bacteria may be considered transient microbial associations (i.e. Serratia, Enterobacter, Escherichia, Erwinia, Pseudomonas and Staphylococcus). Overall, these bacteria were detected at very low prevalence, despite the use of whole psyllid individuals, including the gut. Spiroplasma was found in one G. brimblecombei individual. Different species of Spiroplasma are arthropod-associated symbionts that can impact insect fitness and reproduction $[86,87]$, or they can be plant pathogenic [40] whereby any transmission of plant pathogenic Spiroplasma by psyllids is unknown. Therefore, it is more likely that the Spiroplasma found in G. brimblecombei impacts psyllid fitness rather than plants but this needs further investigation.

One factor that may have contributed to findings of low incidence and prevalence of transient bacteria is the large number of eucalypt-associated species included in this study while the other species were obtained from many host plant taxa. However, there was no overall significant difference in the microbiota of eucalypt-feeding psyllids and psyllids with other host plant associations. It has previously been suggested that antimicrobial effects of plant secondary compounds in eucalypt-feeders may impact their microbiota; however, based on our study, this appears not to be the case for psyllid microbiota. It is far more likely that the feeding mode of psyllids generally limits exposure to microbes [22] other than phloemlimited bacteria (including plant-pathogenic bacteria) that can be acquired through feeding on plant sap [40]. We have detected one psyllid species, A. dobsoni, which may act as a vector of Phytoplasma as a plant-pathogenic bacterium of Allocasuarina. Despite our relatively large sampling effort, we have not detected any other known psyllidvectored pathogens such as Liberibacter; however, a novel Liberibacter isolate has recently been reported in some but not all $A$. solanicola individuals [88]. Perhaps, the potential of gall- and lerp-forming psyllids to act as pathogen vectors is reduced due to the sessile feeding mode of their nymphs that only develop on a single host plant individual, while nymphs of free-living psyllids can move between host plant individuals and therefore acquire pathogens from infected plants and transmit to uninfected plants. Furthermore, only a proportion of psyllid individuals within populations that vector plant pathogenic bacteria may actually be infected (but see [89]). 
The complete absence of chloroplast reads in the $16 \mathrm{~S}$ rRNA gene amplicon data also confirmed the exclusive plant sap diet of psyllids. In contrast, chloroplast $16 \mathrm{~S}$ rRNA genes were detected in microbiota analyses of other plant sap-feeding insects such as thrips [90] and leaf beetles using the same experimental method (AAGH, JLM and MR, personal observation).

\section{Limitations due to primer bias}

The amplicon primers chosen for this study were suitable for amplifying members of the Enterobacteriaceae, such as Arsenophonus and Sodalis, which are known to be present in many psyllid species [3] as well as Wolbachia and other Rickettsiales, which have been detected previously in psyllids and numerous insect species $[9,31]$. The $16 \mathrm{~S}$ rRNA gene amplicon sequencing primers had much lower sequence identity to Carsonella sequences from psyllids, and up to $29 \%$ sequence reads in some individuals were Carsonella, whereas in other individuals Carsonella was not detected at all, although it was subsequently found using Carsonella-specific primers. Previous amplicon sequencing studies have discussed this issue [81] and attempted to mitigate this bias by modifying the amplicon sequencing primers to ensure amplification of the known P-endosymbionts without compromising amplification of other microbial taxa [22]. However, the focus of our experiment was on S-endosymbionts and other bacteria, and therefore, amplicon sequencing primers that did not amplify Carsonella efficiently were ideal and adequately detected the dominance of Enterobacteriaceae as Sendosymbionts in psyllid microbiota. Another study using the same methodology and amplicon sequencing primer set demonstrated that these primers were efficient in amplifying plant pathogens such as Liberibacter and endosymbiont Profftella (Betaproteobacteria) from Diaphorina psyllids (JLM, personal observation). At the same time, our study also demonstrated the potential risk of amplification bias in amplicon sequencing approaches if not complemented by other approaches. For example, bacteria-specific qPCR using Carsonella-, Arsenophonus- and Sodalis-specific primers established that these bacteria were in high densities in host individuals.

Illumina sequencing is prone to substitution errors [51], and such errors can undoubtedly account for many of the SNPs that produce OTUs that are of low read count and present in few individuals, as well as in individuals that harbour a phylogenetically similar OTU with a much greater read count [22]. This serves to bloat the alpha diversity by splitting a single bacterial line into multiple OTUs, but in this study, WGS demonstrated for some hosts that the P- and S-endosymbionts are single clonal associations, as would be expected for vertically transmitted bacteria that pass through a bottleneck each host generation. Such inflation of OTU composition is significant for insects that harbour as few as two microbial associates.

\section{Conclusions}

Psyllids are an excellent model system to investigate the evolutionary transition from facultative to obligate endosymbiosis of bacteria, endosymbiont complementation and replacement. All psyllids displayed a minimal community of a few core bacteria, with each species harbouring the $\mathrm{P}$-endosymbiont Carsonella and mostly a single S-endosymbiont of the family Enterobacteriaceae or other Gammaproteobacteria in each individual of a species. Remarkably, all individuals of five psyllid species harboured two to three abundant Sendosymbionts that were found in all individuals, and these multipartite relationships should be further investigated in the context of P- and S-symbiont complementation and replacement as well as endosymbiont genome evolution. No psyllid individual was without an abundant S-endosymbiont despite previous reports for the absence of bacteria other than Carsonella in a few gall-forming psyllids. On the contrary, the diversity of microbial associations in gall formers was higher than that in free-living psyllids. Unexpectedly, diversity of S-endosymbionts in flush-feeding C. eucalypti and G. brimblecombei was greater in their native range than in the invasive range and invites investigation of the ecological and environmental factors that triggered the losses of S-endosymbionts from invasive populations while these S-endosymbionts appeared fixed in native populations.

\section{Additional files}

Additional file 1: Sampling information for 191 specimens individually subjected to $16 \mathrm{~S}$ rRNA gene amplicon sequencing, including number of reads generated by MiSeq amplicon sequencing before and after quality control, and following chimera removal (XLSX $48 \mathrm{~kb}$ ).

Additional file 2: Primer sequences and PCR conditions (XLSX $11 \mathrm{~kb}$ ).

Additional file 3: List of the nymphs collected for this study. Each nymph sample was subjected to COI amplification and sequencing. Samples with parasitoid DNA present were discarded. The list includes the number of nymphs from each species and site that were subject to DNA extraction, the number of those DNA extractions that were determined to be parasitised and the number of psyllid nymphs remaining that were included in the final 16S rRNA gene amplicon dataset (XLSX $12 \mathrm{~kb}$ ).

Additional file 4: $q P C R$ primer efficiency (XLSX $10 \mathrm{~kb}$ ).

Additional file 5: Microbial OTU richness in 191 individuals of 25 psyllid species (summarised by species). Rarefaction curves were generated for each species from the mean number of observed OTUs (of 10 iterations) calculated from 40 evenly spread sampling depths to an upper limit of 2000 reads. Sampling was performed using alpha_rarefaction.py command within QIIME and the graph was plotted in R (PDF $31 \mathrm{~kb}$ ).

Additional file 6: Alpha diversity metrics (XLSX $21 \mathrm{~kb}$ ).

Additional file 7: OTU table for 191 samples. Original dataset was rarefied to 970 reads (the lowest number of reads in a sample) (XLSX $718 \mathrm{~kb}$ ). 
Additional file 8: Phylogenetic tree estimated using Bayesian inference. The 50 most abundant OTUs from the amplicon sequencing, plus Carsonella sequences either from amplicon or WGS datasets. Full-length or near full-length $16 \mathrm{~S}$ rRNA gene sequences of eight S-endosymbionts were extracted from WGS datasets. Finally, 57 near full-length reference sequences of $\mathrm{P}$ - and $\mathrm{S}$-endosymbionts of Hemiptera were retrieved from GenBank (PDF 13 kb).

Additional file 9: Normalised GPCR results (XLSX $14 \mathrm{~kb}$ ).

Additional file 10: Beta diversity comparison of three distance matrices (unweighted UniFrac, weighted UniFrac and Bray-Curtis), with samples categorised by species, genus, ecological niche, feeding and host plant type (XLSX $9 \mathrm{~kb}$ ).

\section{Acknowledgements}

The authors are grateful to James Cook, Kathryn Raphael, Martin Steinbauer, Gary Taylor and Carlos Valente for the psyllid collections from some populations as outlined in Additional file 1 and to Caroline Janitz and Emma Hackett from the HIE NGS Facility for the amplicon library preparation and sequencing.

\section{Funding}

This research was funded by the Hermon Slade Foundation (HSF 12/10), the NSW Government through its Environmental Trust (2012 MG 0003) and the Hawkesbury Institute for the Environment of Western Sydney University.

\section{Availability of data and materials}

The datasets generated and analysed during the current study are available in the following repositories. DNA sequences: GenBank accession numbers for $\mathrm{COI}$ and cytb genes are listed in Additional file 1. GenBank accession numbers for 165 rRNA gene sequences derived from whole genome sequencing are KY427941-KY427942 and KY428654-KY428661. Raw 16S rRNA gene amplicon reads: NCBI SRA BioProject ID PRJNA381972.

\section{Authors' contributions}

The study was conceptualised and designed by MR and JLM. Most specimens were collected and identified by MR and AAGH. The experiments were performed by JLM. The analyses were performed by JLM and AAGH. JLM and MR wrote the manuscript. All authors read and approved the final manuscript.

\section{Competing interests}

The authors declare that they have no competing interests.

\section{Consent for publication}

Not applicable.

Ethics approval and consent to participate

Not applicable.

\section{Publisher's Note}

Springer Nature remains neutral with regard to jurisdictional claims in published maps and institutional affiliations.

\section{Author details}

${ }^{1}$ Hawkesbury Institute for the Environment, Western Sydney University, Locked Bag 1797, Penrith, NSW 2751, Australia. ${ }^{2}$ Current address: Department of Agriculture and Water Resources, 1 Crewe Place, Rosebery, NSW 2018, Australia.

\section{Received: 14 December 2016 Accepted: 15 May 2017} Published online: 06 June 2017

\section{References}

1. Moran NA, McCutcheon JP, Nakabachi A. Genomics and evolution of heritable bacterial symbionts. Annu Rev Genet. 2008;42:165-90.

2. Morrow JL, Frommer M, Royer JE, Shearman DCA, Riegler M. Wolbachia pseudogenes and low prevalence infections in tropical but not temperate Australian tephritid fruit flies: manifestations of lateral gene transfer and endosymbiont spillover? BMC Evol Biol. 2015;15(1):202.
3. Hall AAG, Morrow JL, Fromont C, Steinbauer MJ, Taylor GS, Johnson SN, Cook JM, Riegler M. Codivergence of the primary bacterial endosymbiont of psyllids versus host switches and replacement of their secondary bacterial endosymbionts. Environ Microbiol. 2016;18(8):2591-603.

4. Wernegreen JJ. Genome evolution in bacterial endosymbionts of insects. Nat Rev Genet. 2002;3(11):850-61.

5. Hansen A, Jeong G, Paine T, Stouthamer R. Frequency of secondary symbiont infection in an invasive psyllid relates to parasitism pressure on a geographic scale in California. Appl Environ Microbiol. 2007;73(23):7531-5.

6. Oliver KM, Russell JA, Moran NA, Hunter MS. Facultative bacterial symbionts in aphids confer resistance to parasitic wasps. Proc Natl Acad Sci U S A. 2003;100(4):1803-7.

7. Chen DQ, Montllor CB, Purcell AH. Fitness effects of two facultative endosymbiotic bacteria on the pea aphid, Acyrthosiphon pisum, and the blue alfalfa aphid, A. kondoi. Entomol Exp Appl. 2000;95(3):315-23.

8. Leonardo TE, Muiru GT. Facultative symbionts are associated with host plant specialization in pea aphid populations. Proc R Soc Lond B Biol Sci. 2003; 270 Suppl 2:S209-12.

9. Gueguen G, Vavre F, Gnankine O, Peterschmitt M, Charif D, Chiel E, Gottlieb Y, Ghanim M, Zchori-Fein E, Fleury F. Endosymbiont metacommunities, mtDNA diversity and the evolution of the Bemisia tabaci (Hemiptera: Aleyrodidae) species complex. Mol Ecol. 2010;19(19):4365-76.

10. Sloan DB, Moran NA. Genome reduction and co-evolution between the primary and secondary bacterial symbionts of psyllids. Mol Biol Evol. 2012; 29(12):3781-92.

11. Pérez-Brocal V, Gil R, Ramos S, Lamelas A, Postigo M, Michelena JM, Silva FJ, Moya A, Latorre A. A small microbial genome: the end of a long symbiotic relationship? Science. 2006;314(5797):312-3.

12. Andersson SGE, Kurland CG. Reductive evolution of resident genomes. Trends Microbiol. 1998;6(7):263-8

13. Feldhaar $\mathrm{H}$. Bacterial symbionts as mediators of ecologically important traits of insect hosts. Ecol Entomol. 2011;36(5):533-43.

14. Zytynska SE, Weisser WW. The natural occurrence of secondary bacterial symbionts in aphids. Ecol Entomol. 2016;41:13-26.

15. Moran NA. Accelerated evolution and Muller's rachet in endosymbiotic bacteria. Proc Natl Acad Sci. 1996;93(7):2873-8.

16. Sloan DB, Nakabachi A, Richards S, Qu J, Murali SC, Gibbs RA, Moran NA. Parallel histories of horizontal gene transfer facilitated extreme reduction of endosymbiont genomes in sap-feeding insects. Mol Biol Evol. 2014;31(4):857-71.

17. Thao ML, Clark MA, Baumann L, Brennan EB, Moran NA, Baumann P. Secondary endosymbionts of psyllids have been acquired multiple times. Curr Microbiol. 2000;41(4):300-4.

18. Thao ML, Baumann P. Evidence for multiple acquisition of Arsenophonus by whitefly species (Sternorrhyncha: Aleyrodidae). Curr Microbiol. 2004 48(2):140-4.

19. Thao ML, Gullan PJ, Baumann P. Secondary ( $\gamma$-Proteobacteria) endosymbionts infect the primary ( $\beta$-Proteobacteria) endosymbionts of mealybugs multiple times and coevolve with their hosts. Appl Environ Microbiol. 2002;68(7):3190-7.

20. Bennett GM, Moran NA. Small, smaller, smallest: the origins and evolution of ancient dual symbioses in a phloem-feeding insect. Genome Biol Evol. 2013; 5(9):1675-88.

21. Urban JM, Cryan JR. Two ancient bacterial endosymbionts have coevolved with the planthoppers (Insecta: Hemiptera: Fulgoroidea). BMC Evol Biol. 2012;12(1):87.

22. Jing $X$, Wong ACN, Chaston JM, Colvin J, McKenzie CL, Douglas AE. The bacterial communities in plant phloem-sap-feeding insects. Mol Ecol. 2014; 23(6):1433-44.

23. Baumann P. Biology of bacteriocyte-associated endosymbionts of plant sapsucking insects. Annu Rev Microbiol. 2005;59:155-89.

24. Thao ML, Moran NA, Abbot P, Brennan EB, Burckhardt DH, Baumann P. Cospeciation of psyllids and their primary prokaryotic endosymbionts. Appl Environ Microbiol. 2000;66(7):2898-905.

25. Fukatsu T, Nikoh N. Two intracellular symbiotic bacteria from the mulberry psyllid Anomoneura mori (Insecta, Homoptera). Appl Environ Microbiol. 1998:64(10):3599-606.

26. Subandiyah S, Nikoh N, Tsuyumu S, Somowiyarjo S, Fukatsu T. Complex endosymbiotic microbiota of the citrus psyllid Diaphorina citri (Homoptera: Psylloidea). Zoolog Sci. 2000;17(7):983-9. 
27. Waku Y, Endo Y. Ultrastructure and life cycle of the symbionts in a homopteran insect, Anomoneura mori Schwartz (Psyllidae). Appl Entomol Zool. 1987;22(4):630-7.

28. Profft J. Beitrage zur Symbiose der Aphiden und Psylliden. Z Morphol Okol Tiere. 1937;32(2):289-326.

29. Nakabachi A, Yamashita A, Toh H, Ishikawa H, Dunbar HE, Moran NA, Hattori M. The 160-kilobase genome of the bacterial endosymbiont Carsonella. Science. 2006;314(5797):267.

30. Moran NA, Bennett GM. The tiniest tiny genomes. Annu Rev Microbiol. 2014;68:195-215

31. Fromont C, Riegler M, Cook JM. Phylogeographic analyses of bacterial endosymbionts in fig homotomids (Hemiptera: Psylloidea) reveal codiversification of both primary and secondary endosymbionts. FEMS Microbiol Ecol. 2016;92:fiw205.

32. Spaulding AW, von Dohlen CD. Psyllid endosymbionts exhibit patterns of co-speciation with hosts and destabilizing substitutions in ribosomal RNA. Insect Mol Biol. 2001;10(1):57-67.

33. Hollis D. Australian Psylloidea jumping plantlice and lerp insects. Canberra: Australian Biological Resources Study; 2004

34. White TCR. The nymphal stage of Cardiaspina densitexta (Homoptera: Psyllidae) on leaves of Eucalyptus fasciculosa. Aust J Zool. 1970;18(3):273-93.

35. Sharma A, Raman A, Taylor G, Fletcher M, Nicol H. Feeding and oviposition behaviour of a gall inducing species of Glycaspis (Synglycaspis) (Hemiptera: Psylloidea: Aphalaridae) and development of galls on the leaves of Eucalyptus macrorhyncha (Myrtaceae) in central western New South Wales, Australia. Eur J Entomol. 2015;112(1):75-90.

36. White TCR. Lerp insect (Cardiaspina densitexta) outbreaks on pink gum (Eucalyptus fasciculosa) in the southeast of South Australia. Austral Ecol. 2016;41:339-41.

37. Steinbauer MJ, Burns AE, Hall AAG, Riegler M, Taylor GS. Nutritional enhancement of leaves by a psyllid through senescence-like processes: insect manipulation or plant defence? Oecologia. 2014;176(4):1061-74.

38. Steinbauer MJ. Shoot feeding as a nutrient acquisition strategy in free-living psylloids. PLoS One. 2013;8(10):e77990.

39. Gherlenda AN, Esveld JL, Hall AAG, Duursma RA, Riegler M. Boom and bust: rapid feedback responses between insect outbreak dynamics and canopy leaf area impacted by rainfall and CO2. Glob Chang Biol. 2016;22:3632-41.

40. Perilla-Henao LM, Casteel CL. Vector-borne bacterial plant pathogens: interactions with hemipteran insects and plants. Front Plant Sci. 2016;7:1163.

41. Burckhardt D, Ouvrard D. A revised classification of the jumping plant-lice (Hemiptera: Psylloidea). Zootaxa. 2012;3509(1):1-34.

42. Morgan FD. Psylloidea of South Australia. South Australia: Handbooks Committee; 1984.

43. Hall AAG, Gherlenda AN, Hasegawa S, Johnson SN, Cook JM, Riegler M. Anatomy of an outbreak: the biology and population dynamics of a Cardiaspina psyllid species in an endangered woodland ecosystem. Agric For Entomol. 2015;17:292-301.

44. Morrow J, Frommer M, Shearman D, Riegler M. The microbiome of fieldcaught and laboratory-adapted Australian tephritid fruit fly species with different host plant use and specialisation. Microb Ecol. 2015;70(2):498-508.

45. Marchesi JR, Sato T, Weightman AJ, Martin TA, Fry JC, Hiom SJ, Wade WG. Design and evaluation of useful bacterium-specific PCR primers that amplify genes coding for bacterial 16S rRNA. Appl Environ Microbiol. 1998;64(2):795-9.

46. O'Neill SL, Giordano R, Colbert AM, Karr TL, Robertson HM. 16S rRNA phylogenetic analysis of the bacterial endosymbionts associated with cytoplasmic incompatibility in insects. Proc Natl Acad Sci U S A. 1992;89(7): 2699-702.

47. Jermiin LS, Crozier RH. The cytochrome $b$ region in the mitochondrial DNA of the ant Tetraponera rufoniger: sequence divergence in hymenoptera may be associated with nucleotide content. J Mol Evol. 1994;38(3):282-94.

48. Simon C, Frati F, Beckenbach A, Crespi B, Liu H, Flook P. Evolution, weighting, and phylogenetic utility of mitochondrial gene sequences and a compilation of conserved polymerase chain reaction primers. Ann Entomol Soc Am. 1994:87(6):651-701.

49. Folmer O, Black M, Hoeh W, Lutz R, Vrijenhoek R. DNA primers for amplification of mitochondrial cytochrome c oxidase subunit 1 from diverse metazoan invertebrates. Mol Mar Biol Biotechnol. 1994;3(5):294-9.

50. Hall AAG, Steinbauer MJ, Taylor GS, Johnson SN, Cook JM, Riegler M: Unravelling mummies: cryptic diversity, host specificity, trophic and coevolutionary interactions in psyllid-parasitoid food webs. BMC Evol Biol. 2017;1-15. doi:10.1186/s12862-017-0959-2.
51. Schirmer M, ljaz UZ, D'Amore R, Hall N, Sloan WT, Quince C. Insight into biases and sequencing errors for amplicon sequencing with the Illumina MiSeq platform. Nucleic Acids Res. 2015;43(6):e37.

52. Caporaso JG, Kuczynski J, Stombaugh J, Bittinger K, Bushman FD, Costello EK, Fierer N, Pena AG, Goodrich JK, Gordon Jl, et al. QIIME allows analysis of highthroughput community sequencing data. Nat Methods. 2010;7(5):335-6.

53. Edgar RC. Search and clustering orders of magnitude faster than BLAST. Bioinformatics. 2010;26(19):2460-1.

54. Altschul SF, Gish W, Miller W, Myers EW, Lipman DJ. Basic local alignment search tool. J Mol Biol. 1990;215(3):403-10.

55. Schmittgen TD, Livak KJ. Analyzing real-time PCR data by the comparative CT method. Nat Protoc. 2008;3(6):1101-8.

56. Hothorn T, Bretz F, Westfall P. Simultaneous inference in general parametric models. Biom J. 2008;50(3):346-63.

57. R Core Team. R: a language and environment for statistical computing. Vienna: R Foundation for Statistical Computing; 2014.

58. Spaulding AW, von Dohlen CD. Phylogenetic characterization and molecular evolution of bacterial endosymbionts in psyllids (Hemiptera: Sternorrhyncha). Mol Biol Evol. 1998;15(11):1506-13.

59. Xue J, Zhou X, Zhang C-X, Yu L-L, Fan H-W, Wang Z, Xu H-J, Xi Y, Zhu Z-R, Zhou W-W, et al. Genomes of the rice pest brown planthopper and its endosymbionts reveal complex complementary contributions for host adaptation. Genome Biol. 2014;15(12):521.

60. Toh H, Weiss BL, Perkin SAH, Yamashita A, Oshima K, Hattori M, Aksoy S. Massive genome erosion and functional adaptations provide insights into the symbiotic lifestyle of Sodalis glossinidius in the tsetse host. Genome Res. 2006;16(2):149-56.

61. Oakeson KF, Gil R, Clayton AL, Dunn DM, von Niederhausern AC, Hamil C, Aoyagi A, Duval B, Baca A, Silva FJ, et al. Genome degeneration and adaptation in a nascent stage of symbiosis. Genome Biol Evol. 2014;6(1):76-93.

62. Lopez-Madrigal S, Latorre A, Porcar M, Moya A, Gil R. Mealybugs nested endosymbiosis: going into the 'matryoshka' system in Planococcus citri in depth. BMC Microbiol. 2013;13:74

63. Kuechler SM, Renz P, Dettner K, Kehl S. Diversity of symbiotic organs and bacterial endosymbionts of lygaeoid bugs of the families Blissidae and Lygaeidae (Hemiptera: Heteroptera: Lygaeoidea). Appl Environ Microbiol. 2012;78(8):2648-59.

64. Moran NA, Dale C, Dunbar H, Smith WA, Ochman H. Intracellular symbionts of sharpshooters (Insecta: Hemiptera: Cicadellinae) form a distinct clade with a small genome. Environ Microbiol. 2003:5(2):116-26.

65. Rouhbakhsh D, Clark MA, Baumann L, Moran NA, Baumann P. Evolution of the tryptophan biosynthetic pathway in Buchnera (aphid endosymbionts): studies of plasmid-associated trpEG within the genus Uroleucon. Mol Phylogenet Evol. 1997;8(2):167-76.

66. Tamura K, Stecher G, Peterson D, Filipski A, Kumar S. MEGA6: molecular evolutionary genetics analysis version 6.0. Mol Biol Evol. 2013;30(12):2725-9.

67. Ronquist F, Teslenko M, van der Mark $P$, Ayres DL, Darling A, Höhna S, Larget B, Liu L, Suchard MA, Huelsenbeck JP. MrBayes 3.2: efficient Bayesian phylogenetic inference and model choice across a large model space. Syst Biol. 2012;61(3):539-42

68. Rambaut A. FigTree 1.4.0. 2012.

69. Gibb KS, Tran-Nguyen LTT, Randles JW. A new phytoplasma detected in the South Australian native perennial shrub, Allocasuarina muelleriana. Ann Appl Biol. 2003;142(3):357-64.

70. Overholt WA, Diaz R, Rosskopf E, Green SJ, Overholt WA. Deep characterization of the microbiomes of Calophya spp. (Hemiptera: Calophyidae) gall-inducing psyllids reveals the absence of plant pathogenic bacteria and three dominant endosymbionts. PLoS One. 2015;10(7): e0132248.

71. Novakova E, Husnik F, Sochova E, Hypsa V. Arsenophonus and Sodalis symbionts in louse flies: an analogy to the Wigglesworthia and Sodalis system in tsetse flies. Appl Environ Microbiol. 2015;81(18):6189-99.

72. Matsuura Y, Kikuchi $Y$, Hosokawa T, Koga R, Meng X-Y, Kamagata Y, Nikoh N Fukatsu T. Evolution of symbiotic organs and endosymbionts in lygaeid stinkbugs. ISME J. 2012;6(2):397-409.

73. Tsuchida T, Koga R, Horikawa M, Tsunoda T, Maoka T, Matsumoto S, Simon J-C, Fukatsu T. Symbiotic bacterium modifies aphid body color. Science. 2010:330(6007):1102-4

74. Meyer JM, Hoy MA. Molecular survey of endosymbionts in Florida populations of Diaphorina citri (Hemiptera: Psyllidae) and its parasitoids Tamarixia radiata (Hymenoptera: Eulophidae) and Diaphorencyrtus 
aligarhensis (Hymenoptera: Encyrtidae). Fla Entomol. 2008;91(2):294-304.

75. Nguyen DT, Spooner-Hart RN, Riegler M. Loss of Wolbachia but not Cardinium in the invasive range of the Australian thrips species, Pezothrips kellyanus. Biol Invasions. 2016;18:197-214.

76. Koga R, Moran NA. Swapping symbionts in spittlebugs: evolutionary replacement of a reduced genome symbiont. ISME J. 2014;8(6):1237-46.

77. Raychoudhury R, Baldo L, Oliveira DC, Werren JH. Modes of acquisition of Wolbachia: horizontal transfer, hybrid introgression, and codivergence in the Nasonia species complex. Evolution. 2009;63(1):165-83.

78. Morrow JL, Frommer M, Shearman DCA, Riegler M. Tropical tephritid fruit fly community with high incidence of shared Wolbachia strains as platform for horizontal transmission of symbionts. Environ Microbiol. 2014;16(12):3622-37.

79. Caspi-Fluger A, Inbar M, Mozes-Daube N, Katzir N, Portnoy V, Belausov E, Hunter MS, Zchori-Fein E. Horizontal transmission of the insect symbiont Rickettsia is plant-mediated. Proc R Soc Lond B Biol Sci. 2012; 279(1734):1791-6.

80. Werren JH, Baldo L, Clark ME. Wolbachia: master manipulators of invertebrate biology. Nat Rev Microbiol. 2008;6(10):741-51.

81. Fromont C, Riegler M, Cook JM: Relative abundance and strain diversity in the bacterial endosymbiont community of a sap-feeding insect across its native and introduced geographic range. Microb Ecol 2017:1-13. doi: 10. 1007/s00248-017-0971-5.

82. Brownlie JC, Cass BN, Riegler M, Witsenburg JJ, Iturbe-Ormaetxe I, McGraw EA, O'Neill SL. Evidence for metabolic provisioning by a common invertebrate endosymbiont, Wolbachia pipientis, during periods of nutritional stress. PLoS Pathog. 2009;5(4):e1000368.

83. Hosokawa T, Koga R, Kikuchi Y, Meng XY, Fukatsu T. Wolbachia as a bacteriocyte-associated nutritional mutualist. Proc Natl Acad Sci U S A. 2010; 107(2):769-74.

84. Sakurai M, Koga R, Tsuchida T, Meng X-Y, Fukatsu T. Rickettsia symbiont in the pea aphid Acyrthosiphon pisum: novel cellular tropism, effect on host fitness, and interaction with the essential symbiont Buchnera. Appl Environ Microbiol. 2005;71(7):4069-75

85. Matsuura Y, Kikuchi Y, Meng XY, Koga R, Fukatsu T. Novel clade of alphaproteobacterial endosymbionts associated with stinkbugs and other arthropods. Appl Environ Microbiol. 2012;78(12):4149-56.

86. Duron O, Bouchon D, Boutin S, Bellamy L, Zhou L, Engelstädter J, Hurst GD. The diversity of reproductive parasites among arthropods: Wolbachia do not walk alone. BMC Biol. 2008;6:27.

87. Fukatsu T, Tsuchida T, Nikoh N, Koga R. Spiroplasma symbiont of the pea aphid, Acyrthosiphon pisum (Insecta: Homoptera). Appl Environ Microbiol. 2001;67(3):1284-91.

88. Morris J, Shiller J, Mann R, Smith G, Yen A, Rodoni B. Novel 'Candidatus Liberibacter' species identified in the Australian eggplant psyllid, Acizzia solanicola. Microbial Biotechnology 2017;1-12. doi:10.1111/1751-7915.12707.

89. Ukuda-Hosokawa R, Sadoyama Y, Kishaba M, Kuriwada T, Anbutsu H, Fukatsu T. Infection density dynamics of the citrus greening bacterium "Candidatus Liberibacter asiaticus" in field populations of the psyllid Diaphorina citri and its relevance to the efficiency of pathogen transmission to citrus plants. Appl Environ Microbiol. 2015;81(11):3728-36.

90. Nguyen DT, Spooner-Hart RN, Riegler M. Polyploidy versus endosymbionts in obligately thelytokous thrips. BMC Evol Biol. 2015;15:23.

\section{Submit your next manuscript to BioMed Central and we will help you at every step:}

- We accept pre-submission inquiries

- Our selector tool helps you to find the most relevant journal

- We provide round the clock customer support

- Convenient online submission

- Thorough peer review

- Inclusion in PubMed and all major indexing services

- Maximum visibility for your research

Submit your manuscript at www.biomedcentral.com/submit 